\title{
Predicting Genetic Demography of Rear-edge Populations of Hemerocallis Middendorffii: A Test for Climate Effects in Last Glacial Maximum and Holocene Optimum
}

Kazutoshi Masuda ( $\nabla$ masuda.kazutoshi.66r@st.kyoto-u.ac.jp )

Kyoto University: Kyoto Daigaku https://orcid.org/0000-0002-4304-0219

Hiroaki Setoguchi

Kyoto University: Kyoto Daigaku

Koki Nagasawa

Kyoto Daigaku

Masae Iwamoto Ishihara

Kyoto Daigaku

Kazuhiro Sawa

Tendou city

Kenji Horie

Asahikawa City Northern Wild Plant Garden

Hayato Tsuboi

Hakubagoryu Alpine Botanical Garden

Shigeru Fukumoto

Ashiu Biological Conservation project

Tsuguoki Tango

Oki gun

Shota Sakaguchi

Kyoto Daigaku

Research article

Keywords: Climate change, EST-SSR, Genetic diversity, Hememrocallis, Population genetics

Posted Date: December 16th, 2020

DOl: https://doi.org/10.21203/rs.3.rs-126637/v1

License: (c) (i) This work is licensed under a Creative Commons Attribution 4.0 International License.

Read Full License 
Page $2 / 34$ 


\section{Abstract}

\section{Background}

Quaternary climate changes significantly impacted population demography of temperate organisms by shifting their distribution. Notably, the rear-edge populations are considered to be more prone to these changes, but empirical studies showed the southernmost fragmented populations of Japanese woody plants to harbor high genetic diversities due to their southern glacial refugia origin. Therefore, the impacts of Holocene climate warming on rear-edge populations have been rarely demonstrated. For the better interpretation of genetic backgrounds of temperate plants, the association of paleodistributions under both icy and warm climates with species-specific demographic changes is required. A perennial daylily Hemerocallis middendorffii (Asphodelaceae) is widely distributed in temperate and cool-temperate zones of East Asia. In Japan, larger populations are found in central ranges, while few small populations survive on harsh rock walls in southernmost regions. We focused on these variable populations and aimed to predict the population demography in relation to past climate changes by statistically combining population genetics with paleodistribution modeling.

\section{Results}

EST-SSR analysis of 737 individuals from 41 populations revealed 6 regional population groups. Four groups widely dominating the northern-central ranges harbored high genetic diversity, whereas genetic divergence within the groups was low. However, two groups at the southwest edge were geographically and genetically isolated and showed the lowest genetic diversity. Estimated paleodistributions showed a decrease of suitable range during Holocene climate optimum in comparison with LGM, and a sole variable of habitat suitability in the Holocene optimum was able to predict genetic diversity across its range.

\section{Conclusions}

We concluded that habitat fragmentation and population decline in relation to the climate warming during the Holocene optimum and interspecific competition with woody plants resulted in genetic isolation and impoverishment of the rear-edge populations.

\section{Backgrounds}

Climate change caused by glacial-interglacial cycles during the Quaternary period produced significant impacts on species distribution and played essential roles in shaping the diversity patterns of contemporary populations [1, 2]. These climatic oscillations drove north-south and highland-lowland migration cycles of plant distribution, which strongly affected their demographic history [3-5]. Therefore, current genetic patterns within species reflect their responses to expansions and contractions of their habitats associated with the climate cycles. Particularly, rear-edge populations, defined as those populations residing at the current low-latitude margins of species distribution ranges in cases of 
Northern Hemisphere [6], are assumed to be influenced the climate cycles strongly because of the marginality of the species that is characterized by ecological, geographical and genetic dimensions [7]. One of the hypotheses about rear-edge populations is that these populations harbor higher genetic diversity, or are genetically divergent to other populations. This is because these populations have endured and persisted the climatic oscillations for a long time in isolated glacial refugia $[1,2]$ with the accumulation of unique genetic variation, compared to leading northern populations, which have low genetic diversity as a result of founder effects [8]. If these populations maintain stable population size during postglacial periods as a result of the discrepancy between ecological and geographical margins [7], for example, they harbor higher genetic diversity even now. Rear-edge populations also adapt locally to cope with warm and dry conditions, which they have faced $[9,10]$, and these adaptations may be a key for species survival in the underway global warming. Thus, rear-edge populations have been considered to be important for the long-term conservation of genetic diversity and for the investigation of phylogenetic history and evolutionary potential of species $[6,11]$.

As an alternative hypothesis, the rear-edge populations may be genetically impoverished, more prone to population decline, and final extinction. These populations may be glacial relicts, barely survived in microrefugia [12] under the influence of ecological, geographical and genetic dimensions such as genetic drifts and low gene flow as a result of isolation or population decline due to the postglacial habitat fragmentation.

Climate changes are still important as determinants of the genetic characteristics of rear-edge populations. Particularly in the case of rear-edge populations, rising temperatures driven by climate warming could amplify drought stress and thus constrain the growth of plants [13], hindering thereby the colonization to new suitable habitats [14] and increasing the risk of population decline. In fact, population decline in rear-edge populations in response to climate change has been reported [15-17]. These conflicting hypotheses about the rear-edge population indicate that populations demography in relation to climate change can be defined as immoderate conditions not only as a cold period but also as a warm period.

Population demography of temperate trees in the Japanese Archipelago in relation to the climatic oscillations have been studied intensively in the last two decades [18-22]. These studies showed that populations in southwestern Japan tend to harbor higher genetic diversity because glacial refugia were located in the south. Whereas lower genetic diversity and unstable demography were observed in northeastern populations. These results suggested that the spatial distribution of glacial refugia during the last glacial period strongly influenced the current genetic diversities of temperate trees. However, the impacts of climate change vary by species and distributed regions [23], and population demography can take idiosyncratic responses even for plants in the same community [24]. Hence, intensive research of plant species with diverse life forms and species characters is essential to test the alternative demographic hypotheses on rear-edge populations. 
Hemerocallis middendorffii Trautv. et C.A.Mey (Asphodelaceae), is a perennial daylily, characterized by a dayflower with an orange-colored perianth undergoing anthesis in the early morning [25]. Pollinator fauna and the presence or absence of self-compatibility of the species have not been investigated, but it may show similar pattern with related species as $H$. fulva L. var. longituba (Miq.) Maxim which is known to be pollinated usually by swallowtail butterflies [26] and self-incompatibility [27]. The seeds are black and globular and are thought to scatter by gravity. This species occurs widely in temperate and cooltemperate zones of East Asia; central and northeastern China, northern and central Korea, southeastern Siberia, Sakhalin, southern part of the Kuril Islands, and northern and central Honshu and Hokkaido Islands of the Japanese Archipelago [25, 28-30] (Fig. 1). In Japan, this species is classified into four intraspecific taxa based on morphological and ecological differences [31, 32]; var. middendorffii (northern Japan), var. esculenta (widespread in central Japan), var. esculenta f. musashiensis (lowland form in central Honshu), and var. exaltata (insular taxon in Tobishima and Sado Isls). The habitats of $H$. middendorffii are variable, including low elevation slopes facing the sea in colder regions, such as Hokkaido and northern Honshu, high-elevation grasslands, wetlands and rock walls in central Honshu, suggesting that this species has a wide climatic tolerance as long as the habitats harbor full sun conditions. In the southernmost ranges of this species, the populations inhabit dry rock outcrops, which prevent the invasions of competitive temperate trees, and thus they are isolated from neighboring populations. The geographic location, local environments, and extent of spatial isolation from other populations may indicate that these limited southern populations have served as rear-edge populations (e.g., those in Oki Isls., Fig. 1) in the archipelago. Therefore, the wide-ranging $H$. middendorffii is considered to be a suitable species to investigate the historical effects of palaeoclimates on the demography of regional populations, and particularly those of rear-edge populations.

The aim of this study is to determine the respective roles of extreme climate stages of late Quaternary in shaping the population demography of $H$. middendorffii in the Japanese Archipelago. In particular, our investigation focuses on rear-edge populations, which can provide opportunities to test whether they have served as glacial refugial populations as reported from many temperate trees, or whether they represent the glacial relicts in which interglacial climates limited the population diversity and demography. In this study, we first performed a phylogeographic analysis to define regional populations based on geographic distribution and intraspecific genetic structure. In order to understand the respective impacts of glacial and interglacial climates, population genetic diversities and reconstructed demographic histories of regional populations were then compared among regions and statistically combined with the paleodistributions predicted by an ecological niche modeling.

\section{Results}

\section{Phylogeographic structure of $\mathrm{H}$. middendorffii complex}

The log-likelihood of the data $L(K)$ and $\Delta K$ were plotted against the number of clusters $(K)$ assumed in the STRUCTURE analysis (Fig. 2). The $L(K)$ continuously increased with increasing number of $K$, while $\Delta K$ showed the highest value at $K=2$ and then a secondary peak at $K=6$, indicating the hierarchical genetic 
structure within the genotype data. The clustering pattern at $\mathrm{K}=2$ showed a north-south differentiation with a phylogeographic break at the central Honshu Island (Fig. 3), which was considered to be the uppermost structure. An increase in the number of populations $(K=3-6)$ detected further regional groups, separated by seaways or geographic features. Taking into account the geographic distribution of genetic clusters, we assumed $\mathrm{K}=6$ to be one optimal number of clusters, and the corresponding genetic structure was biologically interpretable (Fig. 4). Relatively large areas of Hokkaido and the regions to the north of the central Honshu Islands were dominated by blue, light blue, yellow, and orange clusters, respectively, while the southernmost populations in Kyoto Pref. and Oki Isl. were almost fixed to each red and green cluster (Fig. 4). An insular population (Sado Isl.) was unique in terms of having an admixed genetic origin (Fig. 3,4). In accordance with the STRUCTURE clustering, UPGMA network (Fig. 5), the NJ network (Fig. 6) and neighbor-net (Fig. 7) based on $\mathrm{D}_{\mathrm{A}}$ distances detected geographic structuring of the populations, although bootstrap values for the phylogenetic networks were mostly low.

Considering the concordant genetic structure among the different analysis methods and geographical distribution, we defined six regional populations (HK, TO, CH, KI, KY, OK in Table 1, S1), except that an admixed population ("Sado") was excluded from any of the groups due to unclear group assignment.

Table 1

\begin{tabular}{|lllllllll|}
\hline Group & $\mathbf{n}(\mathbf{p n})$ & AR & Ho & Hs & $\mathbf{F}_{\text {IS }}$ & $\mathbf{F}_{\text {ST }}$ & PAR & M \\
\hline Hokkaido (HK) & $106(10)$ & 1.53 & 0.509 & 0.571 & 0.108 & 0.080 & 0.853 & 0.878 \\
\hline Tohoku (TO) & $153(7)$ & 1.62 & 0.591 & 0.630 & 0.061 & 0.036 & 0.831 & 0.863 \\
\hline Chubu (CH) & $184(10)$ & 1.55 & 0.520 & 0.543 & 0.042 & 0.105 & 0.665 & 0.872 \\
\hline Kinki (KI) & $146(7)$ & 1.55 & 0.514 & 0.552 & 0.068 & 0.088 & 0.560 & 0.817 \\
Kyoto (KY) & $87(4)$ & 1.46 & 0.451 & 0.454 & 0.007 & 0.214 & 0.426 & 0.707 \\
\hline Oki (OK) & $45(2)$ & 1.51 & 0.538 & 0.544 & 0.011 & 0.117 & 0.358 & 0.680 \\
\hline P-values & & 0.09 & 0.132 & 0.018 & 0.256 & 0.374 & - & - \\
\hline
\end{tabular}

\section{Genetic diversity among regions and taxa}

Although no significant differences among regional populations were detected for most genetic variation indices (except $\mathrm{H}_{S} ; \mathrm{P}=0.018$ ), there were geographic trends that diversity values of AR (Allelic richness [33]), Ho (observed heterozygosity), Hs (within population gene diversity) were highest in TO and lowest in $\mathrm{KY}$ (Table 1). Relatively high values of pairwise $\mathrm{F}_{\mathrm{ST}}$ were detected in southwestern groups of $\mathrm{KY}$ and OK ( 0.214 and 0.117 , respectively), while $\mathrm{F}_{\mathrm{ST}}$ (Fixation index) of central-northeast regional population pairs in HK and TO and KI showed lower levels (Table 2). However, geographic trends were more evident for two summary statistics (PAR; private allelic richness [34] and M ratio [35]) that are more sensitive to population demographic change, showing a pattern of lower levels from north-eastern to southwestern 
regions (Table 1). Notably, $\mathrm{M}$ ratio of the regional population OK was equal to the common threshold ( $\mathrm{M}$ $=0.68)$ for the genetic bottleneck suggested by Garza and Williamson [35].

Table 2

\begin{tabular}{|lllllll|}
\hline Group & HK & TO & CH & KI & KY & OK \\
\hline Hokkaido (HK) & & & & & \\
\hline Tohoku (TO) & 0.033 & & & & \\
\hline Chubu (CH) & 0.065 & 0.019 & & & \\
\hline Kinki (KI) & 0.075 & 0.056 & 0.063 & & \\
\hline Kyoto (KY) & 0.096 & 0.099 & 0.127 & 0.050 & \\
\hline Oki (OK) & 0.119 & 0.080 & 0.091 & 0.088 & 0.131 \\
\hline
\end{tabular}

Genetic variations were hierarchically partitioned to different layers (i.e., genetic differentiation among regional groups (a) or among taxa (b), among populations, among individuals, within individuals) by AMOVA (Table 3). Comparing the percentage of variations partitioned to the highest layers, the allele frequency differences assigned among regional groups was $10.3 \%$ (Table 3a), which was higher than that among taxa (5.7\%) (Table 3b). The results of AMOVA, together with the STRUCTURE clustering patterns, indicate that population genetic differentiation of $\mathrm{H}$. middendorffii complex can be explained by geographic isolation, but not taxonomy. 


\section{(a) Regions}

\begin{tabular}{|c|c|c|c|c|c|c|c|c|}
\hline $\begin{array}{l}\text { Source of } \\
\text { variation }\end{array}$ & df & SS & $\begin{array}{l}\text { Mean } \\
\text { SS }\end{array}$ & EV & $\%$ & $\begin{array}{l}\text { F- } \\
\text { Statistics }\end{array}$ & Value & $\begin{array}{l}\mathrm{P}(\text { rand }>= \\
\text { data })\end{array}$ \\
\hline Among Regions & 6 & 628 & 104.7 & 0.434 & $10.3 \%$ & $\mathrm{~F}_{\mathrm{RT}}$ & 0.103 & 0.001 \\
\hline $\begin{array}{l}\text { Among } \\
\text { Populations }\end{array}$ & 28 & 486 & 17.3 & 0.336 & $8.0 \%$ & $\mathrm{~F}_{S R}$ & 0.089 & 0.001 \\
\hline $\begin{array}{l}\text { Among } \\
\text { Individuals }\end{array}$ & 689 & 2634 & 3.8 & 0.382 & $9.1 \%$ & $\mathrm{~F}_{S T}$ & 0.183 & 0.001 \\
\hline $\begin{array}{l}\text { Within } \\
\text { Individuals }\end{array}$ & 724 & 2215 & 3.1 & 3.059 & $72.6 \%$ & $\mathrm{~F}_{\mathrm{IS}}$ & 0.111 & 0.001 \\
\hline Total & 1447 & 5963 & & 4.211 & $100.0 \%$ & $\mathrm{~F}_{\mathrm{IT}}$ & 0.274 & 0.001 \\
\hline \multicolumn{9}{|l|}{ (b) Taxa } \\
\hline $\begin{array}{l}\text { Source of } \\
\text { variation }\end{array}$ & df & SS & $\begin{array}{l}\text { Mean } \\
\text { SS }\end{array}$ & EV & $\%$ & $\begin{array}{l}\text { F- } \\
\text { Statistics }\end{array}$ & Value & $\begin{array}{l}\mathrm{P}(\text { rand }>= \\
\text { data) }\end{array}$ \\
\hline Among Taxa & 3 & 207 & 68.9 & 0.247 & $5.7 \%$ & $\mathrm{~F}_{\mathrm{RT}}$ & 0.057 & 0.001 \\
\hline $\begin{array}{l}\text { Among } \\
\text { Populations }\end{array}$ & 31 & 907 & 29.3 & 0.618 & $14.3 \%$ & $F_{S R}$ & 0.152 & 0.001 \\
\hline $\begin{array}{l}\text { Among } \\
\text { Individuals }\end{array}$ & 689 & 2634 & 3.8 & 0.382 & $8.9 \%$ & $\mathrm{~F}_{S T}$ & 0.201 & 0.001 \\
\hline $\begin{array}{l}\text { Within } \\
\text { Individuals }\end{array}$ & 724 & 2215 & 3.1 & 3.059 & $71.1 \%$ & $\mathrm{~F}_{\text {IS }}$ & 0.111 & 0.001 \\
\hline Total & 1447 & 5963 & & 4.306 & $100.0 \%$ & $\mathrm{~F}_{\mathrm{IT}}$ & 0.289 & 0.001 \\
\hline
\end{tabular}

\section{Isolation by distance analysis}

Pairwise genetic distances measured as $\mathrm{F}_{\mathrm{ST}} /\left(1-\mathrm{F}_{\mathrm{ST}}\right)$ were significantly correlated with the pairwise geographic distances for the regional populations of $\mathrm{HK}\left(\mathrm{p}=0.005, \mathrm{R}^{2}=0.449\right.$, Fig. $\left.8 \mathrm{a}\right), \mathrm{CH}\left(\mathrm{p}=0.01, \mathrm{R}^{2}=\right.$ 0.484 , Fig. $8 c), \mathrm{KI}\left(\mathrm{p}=0.024, \mathrm{R}^{2}=0.217\right.$, Fig. $\left.8 d\right)$. In contrast, a significant correlation was rejected for the TO group $\left(p=0.370, R^{2}=0.009\right.$, Fig. $\left.8 b\right)$, and the levels of genetic differentiation in this group were exceptionally low (less than 0.05 ), suggesting an extensive gene flow within the region. The number of populations within regional groups of $\mathrm{KY}$ and $\mathrm{OK}$ was small, so only pairwise distances were shown as dots, which were plotted with regression lines of the other population groups in Fig. 8e. The genetic distances between populations in $\mathrm{KY}$ ranged between 0.1 to 0.2 , which were relatively high considering the short geographic distances among populations (at most $18 \mathrm{~km}$ apart). 


\section{Demographic analysis}

The log-transformed posterior distribution of the ratio of $\mathrm{N}_{\mathrm{C}}$ and $\mathrm{N}_{\mathrm{A}}$ showed the regional differences in population size change in MSVAR analysis (Fig. 9a). The analyses showed that all populations had decreased their population size (i.e., the peak values were below zero), with the population size ratio smallest in $\mathrm{KY}$ followed by OK. The posterior distribution of the time since decline represented a sharp peak at approximately $5 \mathrm{kya}$ in $\mathrm{KY}$, while no clear peaks were detected in other regional populations (Fig. 9b). Temporal size change estimated by VAREFF showed similar demographic trends (Fig. 9c), that the population size of $\mathrm{KY}$ and $\mathrm{OK}$ have been smaller than other regional populations. The intense signal of population declines was detected in $\mathrm{KI}$ and TO around 5kya. Of note, these predicted ages may not be entirely reliable because of the large size per each time step in the posterior range of population, probably due to the relatively small number of markers used in the analyses.

\section{Paleodistribution modeling}

In the MaxEnt analysis, we obtained the mean area under the curve (AUC) value of 0.851 (SD: 0.013). This is above the value of 0.7 that is considered acceptable for model-based predictions [36]. The Holocene optimum distribution of $\mathrm{H}$. middendorffii was predicted based on the assumption that suitable climatic zones existed mainly in Kuril Islands, a coastal area of Hokkaido and Tohoku district, and also higher altitude zone in southern Hokkaido and Honshu Isls. (Fig. 10b), which is similar to the predicted current distribution (Fig. 10a). Meanwhile, the predicted LGM (last glacial maximum) distribution of $\mathrm{H}$. middendorffii showed that suitable habitats mainly existed in more southerly regions, including the central to south-western Japan, where the species are currently absent (Fig. 10c). These predictions indicate that the distribution range shifts would have occurred after the LGM period, which involved the retreats to northern areas and higher altitudinal zones in southerly regions.

\section{Paleodistributions control the extant population genetic diversity}

Arcsin-transformed (asin) He (expected heterozygosity or gene diversity [37]), AR, and PAR were modeled using generalized linear mixed model (GLMM) as a function of habitat suitability during the LGM and Holocene optimum periods. In all genetic diversity indices, the AIC with a combination of a sampling scale of $5 \mathrm{~km}-6 \mathrm{kya}$ and $5 \mathrm{~km}-21 \mathrm{kya}$ were the lowest among the candidate models (Table S2 in Supplementary file 1). As the results of model selection, the model that considered the habitat suitability of $5 \mathrm{~km}-6 \mathrm{kya}$ as a sole explanatory variable was the best among the candidate models for the statistics of asin He and AR (Table S3 and S4 in Supplementary file 1). The estimated coefficients of the fixed term of climatic suitability in Holocene were both significantly positive with 9.96E-03 (SE: 1.73E-03) and 1.55E03 (SE: 3.57E-04) for asin He and AR ( $P=1.55 \mathrm{E}-08$ and 1.80E-05), respectively (see also Fig. 11). Regarding the modeling of PAR, a null model attained the lowest AIC among the candidates, meaning that the habitat suitability was unable to predict PAR of the current populations.

\section{Discussion}




\section{Genetic differentiation of H. middendorffii complex}

The results of AMOVA (Table 3) and STRUCTURE clustering (Fig. 4) showed that population genetic differentiation of $\mathrm{H}$. middendorffii complex mostly reflects geographic factors and disagrees with taxonomy, which is in agreement with previous reports $[25,38]$. Possible explanations for the discrepancy with intraspecific taxonomy include that (1) generation of the taxonomic entities was so recent that the genetic markers failed to detect allele frequency differences, which may apply for the case of $f$. musashiensis (a taxon recognized by a subtle habitat difference [38]), and (2) lineage admixture generated a novel phenotypic population, which is assumed for an insular taxon of var. exaltata (in Sado Isl.) with a complex ancestry (Fig. 4). Therefore, except for one particular case of var. exaltata, our molecular data support a hypothesis that geographic isolation was the primary force to drive the genetic differentiation of populations in the Japanese Archipelago.

\section{Central-peripheral pattern revealed in $\mathrm{H}$. middendorffii in the Japanese Archipelago.}

A combination of population genetic analysis, demographic analysis, and paleodistribution models revealed the regional variation in population responses to past climate changes. Below, we discuss the histories of $\mathrm{H}$. middendorffii populations by focusing on each of three geographic regions, that are central, northern leading-edge, and rear-edge populations.

Central populations such as TO, CH, and KI were located in the center of distribution in both the LGM and following Holocene warming (Fig. 10). The relatively stable demography of these populations (higher M values in Table 1, Fig. 9a) indicates that the central regions would have functioned as long-term refugia for this species, allowing them to maintain the higher genetic diversities (Table 1). One mechanism to shape long-term refugia in this region may be the presence of high-elevation mountain ranges $(>1,500 \mathrm{~m}$ a.s.l.), in which plants can shift their distributions upwards and downwards to stay in the same mountain areas $[4,39]$. The current genetic differentiation was the lowest in the central regions (Table 1 ) and was similar in TO group with $\mathrm{F}_{\mathrm{ST}}=0.036$ and non-significant IBD pattern (Fig. 8b). The finding suggests that the effect of random drifts is mostly cancelled by counteracting gene flow among neighboring populations in the region, where the species is commonly distributed in various habitats [30].

Genetic diversity of $\mathrm{H}$. middendorffii in the Japanese Archipelago was higher in central and lower in northern and southern peripheral regions; a pattern follows the prediction from the "central-peripheral hypothesis" $[40,41]$. The species showed such pattern because the peripheral populations, particularly the rear-edge populations, have lost genetic diversity in relation to population size decline (Fig. 9), which was driven by habitat fragmentation and demographic stochasticity [42-44]. The northern populations are currently seen in coastal and lowland areas of Sakhalin and northern Hokkaido Isl. [30]. Palynological records showed that the territories were once covered by boreal coniferous woodland and dry steppe vegetation during the LGM [45], and it was during the post-glacial period when the temperate plants 
became dominant [46]. In line with the vegetation history, the ENM (ecological niche model) predictions suggested that the expansion of suitable habitats of H. middendorffii took place after the LGM periods, indicating the current northern populations are the leading edges. Slightly lower genetic variations in the HK group (Table 1), compared with the southerly TO, may reflect recent demographic stochasticity associated with post-glacial range expansions toward the north. However, since Hokkaido was connected to the continent by land during the last glacial period, there may have been gene flow between populations in both regions during the last glacial period. More extensive sampling will be needed to verify whether the founder effect really worked.

The two regional populations in $\mathrm{OK}$ and $\mathrm{KY}$ can be considered as the rear-edge populations in $\mathrm{H}$. middendorffii in Japan, as they are both located in southernmost ranges as isolated populations, having lower genetic diversity and experienced demographic bottlenecks (Table 1, Fig. 9). Considering the decrease of suitable range and current geographic isolation predicted by ENM, the rear-edge populations may be glacial relicts of the ancestral populations that once expanded the distributions southward during the glacial period (Fig. 10), as suggested in other cool-temperate plants (e.g., a relictual conifer population of Thuja standishii in Oki Islands) [47].

\section{Holocene optimum controlled the demography of the rear- edge populations}

Which of the climatic extremes of the glacial maximum (cold and dry condition) or climate optimum (warm and wet condition) controlled the population genetic demography has been a controversial topic in understanding the rear-edge plant populations [6]. In this study, the demographic inference revealed that the declines of rear-edge populations occurred in the Holocene epoch (Fig. 9). Also, GLMM model selection showed that the current genetic diversity (He and AR) of $\mathrm{H}$. middendorffii can be explained by habitat suitability in the warmest stage, but not by suitability in the glacial climate (Fig. 11). The positive correlation between genetic diversities and 6kya habitat suitability suggests that the lowest levels of genetic diversity of rear-edge populations were likely shaped by population bottlenecks due to climate warming. This pattern is contrary to many other trees in temperate zones in the Japanese Archipelago, in which current genetic diversities reflect the refugial distributions during glacial period(s) and rear-edge populations are characterized by higher genetic diversity [18-22].

The contrasting genetic consequences can be explained by several reasons. The first consideration is differential life history traits among plant species. Woody plants, which generally have longer life span or gene flow distance than herbs including $\mathrm{H}$. middendorffii, are less susceptible to the drift effects [48]. Moreover, perennial herbs are generally more cold hardy than woody perennials, because they can endure winter seasons with their winter buds in the ground [49]. The fact that the current distribution of $\mathrm{H}$.

middendorffii extends to high latitude zones $\left(\sim \mathrm{N} 54^{\circ}\right)$, where most temperate trees are absent is indicative that the species' northern limits may be controlled by temperature during the growth season. Hence, under the glacial climates, the species may have retained larger-size populations in the northern regions than other temperate woody species did. Second, the rear-edge population of perennial herbs is considered 
more prone to competitive exclusion than woody plants [50]. In addition to the direct effects of climate warming, inter-specific competition with surrounding warm-temperate trees in the rear-edge regions would have been influential for the survival of the light-demanding $\mathrm{H}$. middendorffii, which is currently confined to rock outcrops in these regions. The increased genetic differentiation levels in KY and OK groups would be genetic evidence for severely limited gene flow due to habitat fragmentation in the rear-edge populations (Fig. 8). Therefore, we propose that combined effects of (1) glacial persistence in northern regions such as in northern Hokkaido Isl. and (2) rear-edge population declines due to climate warming and competitions with warm-temperate trees would have led to the unprecedented demographic response of $\mathrm{H}$. middendorffii to climate changes.

\section{Conclusions}

We conclude that habitat deterioration caused by climate warming after the glacial period resulted in genetic isolation and impoverishment of the rear-edge populations of $H$. middendorffii. Although our genetic analysis showed that the species persisted in the Holocene optimum in the southernmost regions, it is uncertain whether the edge populations can similarly respond to and survive the anthropogenic climate warming. Population collapses [51,52] and genetic diversity decreases [53] driven by on-going climate warming are being reported in the world. In the case of $H$. middendorffi, most of the rear-edge populations are already limited to rocky walls, in which extreme summer droughts defoliate the plant populations. Moreover, the populations in the KY region are suffering from herbivory damage by deer, the population size of which has suddenly increased due to reduced snowfall and relaxed hunting pressure in the last two decades [54]. Genetic assessment of the rear-edge populations performed in this study provides insights into the management decisions for the effective conservation strategy of genetically unique populations.

\section{Methods}

\section{Population sampling}

We sampled a piece of leaf of 737 individuals from 41 wild populations of $H$. middendorffii complex throughout its distribution range in the Japanese Archipelago, which included 10 populations of var. middendorffii (HK_01-10), one population of var. exaltata (Sado), 29 of var. esculenta (TO_01-07, CH_01-03, CH_05-10, KI_01-07, KY_01-04, OK_01 and OK_02), and one population of var. esculenta $\mathrm{f}$. musashiensis ( $\mathrm{CH}_{-}$04). Identification of the samples were undertook by KM and SS. In sampling of wild populaions, appropriate permissions have been obtained based on local laws, in necessary. Detailed sampling information and voucher specimen is provided in Table S1 in Supplementary file 1. This species is known to have very small populations in southwest Japan, and regional populations KY and OK used in this study are all populations that remain (The distribution of regional population is derived from the results of STRUCTURE analysis, see results). The Hemerocallis species are known to hybridize between different species under natural conditions [26,55-57], and the inclusion of possible recent hybrids can be problematic in estimating population genetic diversity and demography. Hence, during the sampling we 
collected leaf samples from individuals with open flowers, which can be diagnostic of morphological species. In addition, we included the other congeners (a few individuals of $H$. citrina Baroni var. vespertina (H.Hara) M.Hotta, H. fulva L. var. littorea (Makino) M.Hotta, H. fulva L. var. longituba (Miq.) Maxim., $H$. lilioasphodelus L. var. thunbergii (Baker) M.Hotta) in the following genotyping experiments to detect possible hybrids. The genetic structure analysis of the congeneric species and $\mathrm{H}$. middendorffii demonstrated that no recent interspecific hybrids were included in the genotype data of $737 \mathrm{H}$. middendorffii samples (data not shown).

\section{DNA extraction and genotyping methods}

The leaf samples were immediately dried with silica-gel beads and kept in the dark at room temperature until DNA extraction. The leaf materials (ca. $1.0 \mathrm{~cm}^{2}$ ) were then stored at $-80{ }^{\circ} \mathrm{C}$ in a deep freezer (MDFC8V1-PJ, Panasonic, Japan) and were pulverized with a TissueLyser (Qiagen. Hilden, Germany). After polysaccharides removal with wash medium described in Setoguchi and Ohba [58] from the resulting powder, total DNA was extracted using the CTAB (Cetyltrimethylammonium bromide) method [59]. For genetic analysis, we used 12 EST-SSR markers developed for $H$. middendorffii [60]. The total PCR (polymerase chain reaction) reaction volume was $6 \mu \mathrm{L}$, which contained approximately $0.5 \mathrm{ng} \mathrm{DNA}, 3 \mu \mathrm{L}$ of $2 \times$ QIAGEN Multiplex PCR Master Mix (QIAGEN), $0.01 \mu \mathrm{M}$ of forward primer, $0.2 \mu \mathrm{M}$ of reverse primer, and $0.1 \mu \mathrm{M}$ of fluorescently labeled universal primer which is attached to one of four different universal sequences added to $5^{\prime}$ end of each locus-specific forward primer. PCR amplification was performed with an initial denaturation at $94^{\circ} \mathrm{C}$ for 30 min followed by 35 cycles at $94^{\circ} \mathrm{C}$ for $30 \mathrm{sec}, 55^{\circ} \mathrm{C}$ for $3 \mathrm{~min}$, and $72{ }^{\circ} \mathrm{C}$ for $1 \mathrm{~min}$ followed by a final extension at $68^{\circ} \mathrm{C}$ for $30 \mathrm{~min}$. Amplified products were loaded onto an ABI 3130 auto-sequencer (Applied Biosystems, Foster City, California, USA) using the GeneScan LIZ-600 size standard (Applied Biosystems), POP7 polymer (Applied Biosystems) and 36-cm capillary array. Fragment size was determined using GeneMapper (Applied Biosystems).

\section{Data analysis}

\section{Genetic structure in the Japanese Archipelago}

We employed a model-based Bayesian algorithm implemented in STRUCTURE 2.3.4 [61] to detect genetic structure within the $H$. middendorffii samples. The STRUCTURE analysis was performed according to the assumption that each individual had admixed ancestral origins and different gene pools retained their correlated allele frequency (along with the "correlated allele frequencies model" described by Falush et al. [62]) and that the sampling locations were designated as prior information to obtain better parameter estimates [63]. Twenty independent simulations were run for each $K(K=1-20)$, with 100,000 burn-in steps followed by 100,000 Markov chain Monte Carlo steps. We computed the corresponding $\Delta \mathrm{K}$ ad hoc statistics [64] with STRUCTURE HARVESTER 0.6.94 (http://taylor0.biology.ucla.edu/struct_harvest) [65]. Replicates were combined with CLUMPP [66] and bar plots of assignment probabilities were built using DISTRUCT 1.1. [67] 
The genetic structure among populations was explored by constructing neighbor-joining (NJ) [68] and UPGMA networks based on $D_{\mathrm{A}}$ distance [69] among populations, and the significance of interior branches of the tree was evaluated based on bootstrap values using a software POPTREE2 [70]. We also calculated pairwise $D_{\mathrm{A}}$ distance among populations using GenAlEx 6.51 [71]. This matrix was then used to construct Neighbor-net using Splits Tree4 [72].

Because both model-based and distance-based clustering analyses revealed six population groups corresponding to geographic distributions (see results), all populations were classified to six regional groups; that is HK (Hokkaido), TO (Tohoku district), $\mathrm{CH}$ (Chubu district), KI (Kinki district), KY (Kyoto prefecture), and OK (Oki Isls). The following genetic diversity and demographic analyses were performed separately for the population groups.

\section{Isolation by distance analysis}

To determine the extent of gene flow within a regional population, the presence of significant isolation-bydistance patterns within the six regional populations was investigated by applying the Mantel test with 999 permutations to the pairwise relationship between the log-transformed geographic distances (transformed to natural logarithms) and pairwise $F_{\mathrm{ST}} /\left(1-F_{\mathrm{ST}}\right)$ values between populations [73] using GenAlEx 6.51.

\section{Calculation of genetic diversity}

The levels of within-population genetic diversity were evaluated by calculating four genetic diversity statistics using GenAlEx 6.51: average number of alleles per locus $(N A), H_{0}$, and fixation index $\left(F_{\mathrm{IS}}\right)$. $A R$ and PAR were calculated by HP-Rare [74]. By the calculation of allelic richness using the rarefaction method, which can be used to compare allele diversity between populations with different sizes, the standard sample size was set to more than six individuals in this study. $M$ ratio, which evaluates the effect of a population bottleneck, was calculated for the populations with sample size more than 10 individuals following the method described by Garza and Williamson [35]. We also compared the levels of genetic variation $\left(A R, H o, H e, F_{\mathrm{IS}}\right.$, and $\left.F_{\mathrm{ST}}\right)$ among regional populations as defined above. For testing the effect of population grouping, regional genetic diversity and two-sided $P$-values after 1,000 permutations were assessed using FSTAT 2.9.4 [75].

\section{Genetic differentiation among regions and taxa}

Previous genetic studies of $H$. middendorffii were performed to reveal phylogenetic relationships between H. middendorffii populations, using universal molecular markers, i.e. chloroplast DNA [25, 76], Random Amplified Polymorphic DNA (RAPD) [38] and anonymous single nucleotide polymorphisms (SNPs) from genotyping-by-sequencing [77]. These molecular phylogenetic studies showed that some intraspecific clades were weakly associated with geography. However, because these studies analyzed only one or a few samples per population, no information is available on genetic diversity and demographic changes of regional populations. 
To evaluate the contribution rate of genetic differentiation among regions and taxa, we performed a hierarchical analysis of molecular variance [78]. Calculation of regional $F$-statistics $\left(F_{\mathrm{RT}}, F_{\mathrm{SR}}, F_{\mathrm{ST}}, F_{\mathrm{IS}}\right.$, and $\left.F_{\mathrm{IT}}\right)$ and their significance using the permutation approach were carried out using the program GenAlEx 6.51. Genetic diversity was hierarchically partitioned into four levels: (1) among taxa (a) or among regions (b), (2) among populations, (3) among individuals, and (4) within individuals. In the analysis of the region model, we set up seven regional groups, i.e., the six regional groups defined by STRUCTURE analysis and one group consisted of the Sado Isl. population (which was genetically "admixed"; see results).

\section{Demographic analysis}

We used a full-likelihood Bayesian method MSVAR 1.3 [79], which is efficient at detecting population declines and expansions from microsatellite data, which provided neither too weak nor too recent event. MSVAR is also superior to moment-based methods (the $M$ ratio test and Bottleneck) for detecting changes in population size, independent of time and the severity of the event [80]. For the analysis based on coalescent simulations, we employed 10 microsatellite markers that appeared to follow the stepwise mutation model (excluded two markers: hem19141 and hem15494). We estimated the current and ancestral effective population sizes of regional populations $\left(N_{\mathrm{C}}\right.$ and $\left.N_{\mathrm{A}}\right)$, and the time since the population size started to change. Prior distributions were set as follows: starting value for current and ancestral population size was $10^{3}$ for all loci, mutation rate was $10^{-4}$, starting values for time since decline/expansion for all loci were $10^{4}, \log _{10}$ scale for the prior means and variance of current size, ancestral size, mutation rate and time since decline/expansion were $(4,1),(4,1),(-4,2)$, and $(4.5,2)$, respectively. Generation time was assumed to be 10 years, by considering 4 years as the time to maturation and 6 years as continuing reproduction period.

To infer the changes in each regional population size, we used $R$ package VAREFF, an approximate likelihood method with a Monte Carlo Markov Chain approach [81]. VAREFF is especially useful to provide evidence of transient changes in population size in the past. In this analysis, we set the parameters as follows: NBLOC: 10, JMAX: 5, MODEL: Geometric Model, and provided an additional coefficient (C) for G models: 0.2. MUTAT (mutation rate, assumed the same for all loci): $10-4, \mathrm{NB} A R$ (prior value for the effective size): 3000, VARP1: 3, RHOCORN: 0, GBAR: 3000, VARP2: 3, DMAXPLUS: appropriate values were determined for each regional population. Diagonale: 0.5 , NumberBatch (number of batches for metrop in MCMC): 10000, LengthBatch (length of batch for metrop in MCMC): 10, SpaceBatch (space of batch for metrop in MCMC): 10, Burnin (length of the burnin period): 10000, and AccRate: 0.25).

\section{Paleodistribution modeling}

Ecological niche modeling (ENM) is a powerful tool for revealing distribution changes in the past times. ENM can also provide a source of evidence independent from genetic data, which is particularly pertinent for species that are poorly represented in the fossil records. Once current occurrence data and environmental variables are collated in an ecological niche model, historical species distributions can be approximated by projecting species parameters onto a simulated past climate [82]. 
Because the results of our demographic analyses showed that effective population size changes happened since or after the last glacial period (see results), our paleodistribution modeling targeted the two historical times that represented either climatic extremes: The Last Glacial Maximum (LGM, about 21,000 years ago) and the Holocene optimum, (about 6,000 years ago). For the generation of ENM for $H$. middendorffii, a maximum entropy algorithm implemented in MaxEnt version 3.3.3 k [83] was used to relate occurrence records to the current climate variables. These records were collected either from our original field surveys or specimen records downloaded from the GBIF website (https://www.gbif.org/). After the removal of doubtful records, 271 records were used for model construction. We considered nine bioclimatic variables as predictors, which represented influential factors in terms of temperature and precipitation controls of the species and did not show significant clamping effects in model projections (annual mean temperature, temperature seasonality, mean temperature of the coldest quarter, mean temperature of the warmest quarter, annual precipitation, precipitation of the warmest quarter, precipitation of the coldest quarter, precipitation of the wettest quarter and precipitation of the driest quarter). Current climate and paleoclimate layers during the $21 \mathrm{kya}-\mathrm{CCSM}$ (LGM) and 6kya-CCSM (Holocene optimum) in 30 arc-sec resolution were downloaded from the Worldclim database (https://www.worldclim.org/)[84]. In MaxEnt analysis, 10,000 background points were randomly generated for the study area (the Japanese Islands and Sakhalin), and other parameters were set as defaults, except regularization multiplier as 2 , to avoid model overfitting. To evaluate the optimal quality of the prediction, 100 replicated bootstrapping was performed.

\section{Relationship between paleodistribution and genetic diversity of the extant population}

The values of genetic diversity indices estimated from microsatellite data and paleodistribution reconstructed from current climatic variables and species distribution records were estimated independently. Therefore, the combination of these two approaches can significantly improve our understandings of the past processes, which were shaped through population genetic diversity [85-87].

To test which of the glacial or interglacial climates were the limiting factor of the current population genetic diversity of $\mathrm{H}$. middendorffii, we examined the correlation between genetic diversity estimates and climate suitability around the focal populations, as predicted by ENM. We analyzed three different genetic diversity measures (AR: allelic richness, PAR: private allelic richness, and asin He: arcsine-transformed gene diversity) of the current populations as a function of habitat suitability during the LGM (21 kya) and the Holocene optimum (6kya). The distribution probability of $H$. middendorffii populations during the LGM and Holocene optimum were summed around each population locality, and hereafter, this value will be called "habitat suitability". The projected distribution probability given for each 30-sec pixel within the study area was sampled and summed within multiple-ring buffers using ArcGIS 9.2 Desktop (ESRI, California, USA). Multiple-ring buffers were generated from all sampled locations except for the population number of individuals less than six using QGIS 2.14 (QGIS Development Team). We changed buffer radius from 5 to $300 \mathrm{~km}(5,10,25,50,100,150,200,250,300)$ as an estimated effect of the fixed term may vary according to the spatial scale with which habitat suitability was evaluated [20]. We used a 
generalized linear mixed model (GLMM) to analyze the genetic diversity indices with two fixed terms of habitat suitability at $21 \mathrm{kya}$ and $6 \mathrm{kya}$, in which the loci as random intercepts, because diversity values at these loci are likely to be more related to each other than to the values from different loci. To explore the combination of spatial scales best explaining genetic variations in each genetic diversity index, we selected the most parsimonious model with minimum Akaike's information criterion (AIC) value among the candidate models. We used R-package Ime4 [88] to obtain AIC values among combinations of the different sizes of sampling radius of $21 \mathrm{kya}$ and $6 \mathrm{kya}(9 \times 9$ scales). Model selection was performed by Rpackage MuMIn [89]. Parameters of the best models were estimated by R-package ImerTest [90]. All statistical analyses were conducted in R 3.5.2 (R Development Core Team 2018).

\section{Abbreviations}

$A R$ : allelic richness; ENM: ecological niche model; EST-SSR: expressed-sequence-tag simple sequence repeat; GLMM: generalized linear mixed model; He: expected heterozygosity; Ho: observed heterozygosity; Hs: within population diversity; PAR: private allelic richness, PCR: polymerase chain reaction; LGM: last glacial maximum.

\section{Declarations}

\section{Availability of data and materials}

The datasets generated or analyzed during this study are included in this published article (and its supplementary information files: Supplementary file2).

\section{Acknowledgements}

The authors are grateful to the following people who assisted the material collections: Y. Kato, T. Shiga, D. Fujiki, A. Takayanagi, T. Iwasaki, L. Mizusawa, T. Fukuda, J. Nagasawa, D. Takahashi, K. Magota, H. Kawakita, H. Yanagita, H. Tajima, N. Shirai. Research permissions were provided by Field Science Education and Research Center (Kyoto University), Kuta Forest Research Station (Kyoto Prefectural University), and Ministry of the Environment of Japan.

\section{Authors' Contributions}

$\mathrm{KM}$ and SS conceived and designed the research. Sample collection was conducted by KM, HS, KN, KS, $\mathrm{KH}, \mathrm{HT}, \mathrm{SF}, \mathrm{TT}$, SS in the fields. KM, KN and SS performed research and analyzed data. KM and SS wrote the manuscript. HS, KN and MIl participated in drafting of the manuscript. All authors read and approved the final manuscript. 


\section{Funding}

This work was supported by the TAKARA Harmonist Fund for SS, the Nippon Life Insurance Foundation Fund for MII., the Pro Natura Foundation Japan for the Ashiu Biological Conservation project and the Environmental Research and Technology Development Fund of the Ministry of the Environment (\#41702) for HS and SS. The funding bodies played no role in the design of the study and collection, analysis, and interpretation of data and in writing the manuscript.

\section{Ethics approval and consent to participate}

Not applicable.

\section{Consent for publication}

Not applicable.

\section{Competing Interests}

The authors declare no conflict of interest.

\section{Author details}

${ }^{1}$ Graduate School of Human and Environmental Studies, Kyoto University, Yoshida-Nihonmatsu-cho, Sakyo-ku, Kyoto 606-8501, Japan. ${ }^{2}$ Graduate School of Global Environmental Studies, Kyoto University, Yoshida-Honmachi, Sakyo-ku, Kyoto 606-8501, Japan. ${ }^{3}$ Ashiu Forest Research Station, Field Science Education and Research Center, Kyoto University, Ashiu, Miyama-cho, Nantan-shi, Kyoto, 601-0703, Japan. ${ }^{4}$ Tendou, Yamagata, Japan. ${ }^{5}$ Asahikawa City Northern Wild Plants Garden, Hokkaido, Japan. ${ }^{6}$ Hakubagoryu Alpine Botanical Garden, Nagano, Japan. ${ }^{7}$ Ashiu Biological Conservation project, Kyoto, Japan. ${ }^{8}$ Oki gun, Shimane, Japan.

\section{References}

1. Hewitt G. The genetic legacy of the Quaternary ice ages. Nature. 2000;405(6789):907.

2. Hewitt G. Genetic consequences of climatic oscillations in the Quaternary. Philos Trans R Soc B. 2004; 359(1442):183-195.

3. Taberlet P, Fumagalli L, WUST-SAUCY AG, COSSON JF. Comparative phylogeography and postglacial colonization routes in Europe. Mol Ecol. 1998; 7(4):453-464. 
4. Davis MB, Shaw RG. Range shifts and adaptive responses to Quaternary climate change. Science 2001;292(5517):673-679.

5. Qiu Y-X, Fu C-X, Comes HP. Plant molecular phylogeography in China and adjacent regions: tracing the genetic imprints of Quaternary climate and environmental change in the world's most diverse temperate flora. Mol Phylogenet Evol. 2011(1);59:225-244.

6. Hampe A, Petit RJ. Conserving biodiversity under climate change: the rear edge matters. Ecol Lett. 2005;8(5):461-467.

7. Vilà-Cabrera A, Premoli AC, Jump AS. Refining predictions of population decline at species' rear edges. Glob Change Biol. 2019;25(5):1549-1560.

8. Birkeland S, Skjetne IEB, Brysting AK, Elven R, Alsos IG. Living on the edge: Conserv Genet. of seven thermophilous plant species in a high Arctic archipelago. AoB Plants. 2017;9(1).

9. Cavin L, Jump AS. Highest drought sensitivity and lowest resistance to growth suppression are found in the range core of the tree Fagus sylvatica L. not the equatorial range edge. Glob Change Biol. 2017;23(1):362-379.

10. Granda E, Alla A, Laskurain N, Loidi J, Sánchez-Lorenzo A, Camarero J. Coexisting oak species, including rear-edge populations, buffer climate stress through xylem adjustments. Tree Physiol. 2018;38(2):159-172.

11. Fady B, Aravanopoulos FA, Alizoti P, Mátyás $C$, von Wühlisch G, Westergren M, Belletti P, Cvjetkovic B, Ducci F, Huber G: Evolution-based approach needed for the conservation and silviculture of peripheral forest tree populations. For Ecol Manag. 2016;375:66-75.

12. Rull V: Microrefugia. J Biogeogr. 2009;36(3):481-484.

13. Sánchez-Salguero R, Camarero JJ, Gutiérrez E, González Rouco F, Gazol A, Sangüesa-Barreda G, Andreu-Hayles L, Linares JC, Seftigen K. Assessing forest vulnerability to climate warming using a process-based model of tree growth: Bad prospects for rear-edges. Glob Change Biol 2017;23(7):2705-2719.

14. Honnay O, Verheyen K, Butaye J, Jacquemyn H, Bossuyt B, Hermy M. Possible effects of habitat fragmentation and climate change on the range of forest plant species. Ecol Lett. 2002;5(4):525-530.

15. Reich PB, Sendall KM, Rice K, Rich RL, Stefanski A, Hobbie SE, Montgomery RA. Geographic range predicts photosynthetic and growth response to warming in co-occurring tree species. Nat Clim Chang. 2015;5(2):148-152.

16. Marqués L, Camarero JJ, Gazol A, Zavala MA. Drought impacts on tree growth of two pine species along an altitudinal gradient and their use as early-warning signals of potential shifts in tree species distributions. For Ecol Manag. 2016;381:157-167.

17. Lesica $P$, Crone EE. Arctic and boreal plant species decline at their southern range limits in the Rocky Mountains. Ecol Lett. 2017;20(2):166-174.

18. Fujii N, Tomaru N, Okuyama K, Koike T, Mikami T, Ueda K: Chloroplast DNA phylogeography of Fagus crenata (Fagaceae) in Japan. Plant Syst Evol. 2002;232(1-2):21-33. 
19. Tsumura Y, Kado T, Takahashi T, Tani N, Ujino-Ihara T, Iwata H. Genome scan to detect genetic structure and adaptive genes of natural populations of Cryptomeria japonica. Genetics. 2007;176(4):2393-2403.

20. Sakaguchi S, Takeuchi Y, Yamasaki M, Sakurai S, Isagi Y. Lineage admixture during postglacial range expansion is responsible for the increased gene diversity of Kalopanax septemlobus in a recently colonised territory. Heredity 2011;107(4):338.

21. Sugahara K, Kaneko Y, Ito S, Yamanaka K, Sakio H, Hoshizaki K, Suzuki W, Yamanaka N, Setoguchi $\mathrm{H}$. Phylogeography of Japanese horse chestnut (Aesculus turbinata) in the Japanese Archipelago based on chloroplast DNA haplotypes. J Plant Res. 2011;124(1):75-83.

22. Tamaki I, Kawashima N, Setsuko S, Itaya A, Tomaru N. Morphological and genetic divergence between two lineages of Magnolia salicifolia (Magnoliaceae) in Japan. Biol J Linn Soc. 2018;125(3):475-490.

23. Lumibao CY, Hoban SM, McLachlan J. Ice ages leave genetic diversity 'hotspots' in Europe but not in Eastern North America. Ecol Lett 2017;20(11):1459-1468.

24. Bai WN, Yan PC, Zhang BW, Woeste KE, Lin K, Zhang DY. Demographically idiosyncratic responses to climate change and rapid Pleistocene diversification of the walnut genus Juglans (Juglandaceae) revealed by whole-genome sequences. New Phytol. 2018;217(4):1726-1736.

25. Noguchi J, Hong D-Y, Grant W. The historical evolutionary development of Hemerocallis middendorfii (Hemerocallidaceae) revealed by non-coding regions in chloroplast DNA. Plant Syst Evol. 2004;247(1-2):1-22.

26. Hasegawa M, Yahara T, Yasumoto A, Hotta M. Bimodal distribution of flowering time in a natural hybrid population of daylily (Hemerocallis fulva) and nightlily (Hemerocallis citrina). J Plant Res. 2006;119(1):63-68.

27. Yasumoto AA, Yahara T. Post-pollination reproductive isolation between diurnally and nocturnally flowering daylilies, Hemerocallis fulva and Hemerocallis citrina. J Plant Res. 2006;119(6):617-623.

28. Barkalov VY. Plantae vasculares orientis extremi sovietici [Vascular plants of Soviet Far East]: Leningrad: Nauka. 1987;2: 393-397.

29. Barkalov VY. Flora of the Kuril Islands. Vladivostok: Dalnauka. 2009;257-258.

30. Ohashi H, Kadota Y, Murata J, Yonekura k, Kihara H. Wild Flowers of Japan. 2015.

31. Hiyama K. Flowering plants and ferns of Musashino. Inoue book company: Tokyo. 1965;p. 55.

32. Matsuoka M, Hotta M. Classification of Hemerocallis in Japan and its vicinity (in Japanese). Acta Phytotax Geobot; 1966: 25-43.

33. El Mousadik A, Petit R. High level of genetic differentiation for allelic richness among populations of the argan tree [Argania spinosa (L.) Skeels] endemic to Morocco. Theor Appl Genet. 1996;92(7):832839.

34. Kalinowski ST: Counting alleles with rarefaction: private alleles and hierarchical sampling designs. Conserv Genet. 2004;5(4):539-543. 
35. Garza J, Williamson E. Detection of reduction in population size using data from microsatellite loci. Mol Ecol. 2001;10(2):305-318.

36. Pearce J, Ferrier S. Evaluating the predictive performance of habitat models developed using logistic regression. Ecol Model. 2000;133(3):225-245.

37. Nei M. Estimation of average heterozygosity and genetic distance from a small number of individuals. Genetics. 1978;89(3):583-590.

38. Wakui K, Ran M, Kenji K, Junzo F. RAPD analysis to Evaluate the Genetic Variation and Relationships in Japanese Hemerocallis spp. J Agric Sci, Tokyo Unive Agri. 2013;57(4):293-299.

39. Bennett KD, Bennett K. Evolution and ecology: the pace of life. Cambridge University Press. 1997.

40. Vucetich JA, Waite TA. Spatial patterns of demography and genetic processes across the species' range: null hypotheses for landscape Conservation Genetics. Conserv Genet. 2003;4(5):639-645.

41. Eckert C, Samis K, Lougheed S. Genetic variation across species' geographical ranges: the centralmarginal hypothesis and beyond. Mol Ecol. 2008;7(5):1170-1188.

42. Lönn M, Prentice HC. Gene diversity and demographic turnover in central and peripheral populations of the perennial herb Gypsophila fastigiata. Oikos. 2002;99(3):489-498.

43. Pironon S, Villellas J, Morris WF, Doak DF, García MB. Do geographic, climatic or historical ranges differentiate the performance of central versus peripheral populations? Glob Ecol Biogeogr. 2015;24(6):611-620.

44. Papuga G, Gauthier P, Pons V, Farris E, Thompson J. Ecological niche differentiation in peripheral populations: a comparative analysis of eleven Mediterranean plant species. Ecography. 2018;41(10):1650-1664.

45. Igarashi $Y$, Yamamoto $M$, Ikehara K. Climate and vegetation in Hokkaido, northern Japan, since the LGM: Pollen records from core GH02-1030 off Tokachi in the northwestern Pacific. J Asian Earth Sci. 2011;40(6):1102-1110.

46. Igarashi Y. A Lateglacial climatic reversion in Hokkaido, Northeast Asia, inferred from the Larix pollen record. Quat Sci Rev. 1996;15(10):989-995.

47. Worth JR. Current distribution and climatic range of the Japanese endemic conifer Thuja standishii (Cupressaceae). Bulletin of FFPRI. 2019;18(3):275-288.

48. Hamrick JL, Godt MW. Effects of life history traits on genetic diversity in plant species. Philos Trans R Soc Lond B Biol Sci. 1996;351(1345):1291-1298.

49. Precht H, Christophersen J, Hensel H, Larcher W. Temperature and Life. Springer-Verlag New York Heidelberg Berlin. 1973;p.161.

50. Yasuda N, Noda T, Yagihashi T, Kajimoto T. Introduction to Ecology. Tokyo Douzin. 2012;p.194-196.

51. Franco AM, Hill JK, Kitschke C, Collingham YC, Roy DB, Fox R, Huntley B, Thomas CD. Impacts of climate warming and habitat loss on extinctions at species' low-latitude range boundaries. Glob Change Biol 2006;12(8):1545-1553. 
52. Chen I-C, Hill JK, Ohlemüller R, Roy DB, Thomas CD. Rapid range shifts of species associated with high levels of climate warming. Science 2011. 333(6045):1024-1026.

53. Chala D, Brochmann C, Psomas A, Ehrich D, Gizaw A, Masao CA, Bakkestuen V, Zimmermann NE. Good-bye to tropical alpine plant giants under warmer climates? Loss of range and genetic diversity in Lobelia rhynchopetalum. Ecol Evol. 2016;6(24):8931-8941.

54. Kato M, Okuyama Y. Changes in the biodiversity of a deciduous forest ecosystem caused by an increase in the sika deer population at Ashiu, Japan. Contr biol Lab Kyoto Univ. 2004;29:437-448.

55. Kawano S. On the natural hybrid population of Hemerocallis. Can J Bot. 1961;39(3):667-681.

56. Hotta M, Ito M, Okada I. Anthesis of the genus Hemerocallis and its variation. Special mentions to nocturnal $H$. thunbergii of Tsushima \& Hirado Islands, Western Japan (In Japanese). Acta Phytotax Geobot. 1984; 35.

57. Yahara T. Exploring the genetic backgrounds of differentiation in floral scent and flower color between daylily and nightlily (In Japanese). Bunrui. 2007;93-110.

58. Setoguchi H, Ohba H. Phylogenetic relationships in Crossostylis (Rhizophoraceae) inferred from restriction site variation of chloroplast DNA. J Plant Res. 1995;108(1):87-92.

59. Doyle JJ, Doyle JL: A rapid DNA isolation procedure for small quantities of fresh leaf tissue. Phytochem Bull. 1987;19:11-15.

60. Masuda K, Hiroaki S, Koki N, Masae I, Shota S. Development and characterization of EST-SSR markers for Amur daylily, Hemerocallis middendorffii Trautv. et C.A.Mey. (Asphodelaceae). Acta Phytotax Geobot. (in press)

61. Pritchard JK, Stephens M, Donnelly P. Inference of population structure using multilocus genotype data. Genetics 2000;155(2):945-959.

62. Falush D, Stephens M, Pritchard JK. Inference of population structure using multilocus genotype data: linked loci and correlated allele frequencies. Genetics 2003;164(4):1567-1587.

63. Hubisz MJ, Falush D, Stephens M, Pritchard JK. Inferring weak population structure with the assistance of sample group information. Mol Ecol Res. 2009;9(5):1322-1332.

64. Evanno G, Regnaut S, Goudet J. Detecting the number of clusters of individuals using the software STRUCTURE: a simulation study. Mol Ecol. 2005;14(8):2611-2620.

65. Earl DA: STRUCTURE HARVESTER: a website and program for visualizing STRUCTURE output and implementing the Evanno method. Conserv Genet Resour. 2012;4(2):359-361.

66. Jakobsson M, Rosenberg NA. CLUMPP: a cluster matching and permutation program for dealing with label switching and multimodality in analysis of population structure. Bioinformatics. 2007; 23(14):1801-1806.

67. Rosenberg NA. DISTRUCT: a program for the graphical display of population structure. Mol Ecol Notes. 2004;4(1):137-138.

68. Saitou N, Nei M. The neighbor-joining method: a new method for reconstructing phylogenetic trees. Mol Biol Evol. 1987;4(4):406-425. 
69. Nei M, Takezaki N. Estimation of genetic distances and phylogenetic trees from DNA analysis. Proc 5th World Cong Genet Appl Livstock Prod 1983;21(21):405-412.

70. Takezaki N, Nei M, Tamura K. POPTREEW: web version of POPTREE for constructing population trees from allele frequency data and computing some other quantities. Mol Biol Evol. 2014;31(6):1622-1624.

71. Peakall R, Smouse PE. GENALEX 6: genetic analysis in Excel. Population genetic software for teaching and research. Mol Ecol Notes. 2006;6(1):288-295.

72. Huson DH: SplitsTree: analyzing and visualizing evolutionary data. Bioinformatics (Oxford, England) 1998;14(1):68-73.

73. Rousset F. Genetic differentiation and estimation of gene flow from F-statistics under isolation by distance. Genetics 1997;145(4):1219-1228.

74. Kalinowski ST: hp-rare 1.0: a computer program for performing rarefaction on measures of allelic richness. Mol Ecol Notes. 2005;5(1):187-189.

75. Goudet J. FSTAT (version 1.2): a computer program to calculate F-statistics. J Hered. 1995;86(6):485-486.

76. Noguchi J, Tasaka M, Iwabuchi M. The historical differentiation process in Hemerocallis middendorfii (Liliaceae) of Japan based on restriction site variations of chlorplast DNA. J Plant Res. 1995;108(1):41-45.

77. Murakami S, Takayama K, Fuse S, Hirota SK, Koi S, Ideno T, Yamamoto T, Tamura MN. Recircumscription of Sections of Hemerocallis (Asphodelaceae) from Japan and adjacent regions based on MIG-seq Data. Acta Phytotax Geobot. 2020;71(1):1-11.

78. Excoffier L, Smouse PE, Quattro JM. Analysis of molecular variance inferred from metric distances among DNA haplotypes: application to human mitochondrial DNA restriction data. Genetics. 1992;131(2):479-491.

79. Storz JF, Beaumont MA. Testing for genetic evidence of population expansion and contraction: an empirical analysis of microsatellite DNA variation using a hierarchical Bayesian model. Evolution. 2002;56(1):154-166.

80. Girod $C$, Vitalis R, Leblois R, Fréville $H$. Inferring population decline and expansion from microsatellite data: a simulation-based evaluation of the Msvar method. Genetics. 2011;188(1):165-179.

81. Nikolic N, Chevalet C. Detecting past changes of effective population size. Evol Appl. 2014;7(6):663681.

82. Svenning J-C, Baktoft $\mathrm{KH}$, Balslev $\mathrm{H}$. Land-use history affects understorey plant species distributions in a large temperate-forest complex, Denmark. J Plant Ecol. 2008;221-234.

83. Phillips SJ, Anderson RP, Schapire RE. Maximum entropy modeling of species geographic distributions. Ecol Model. 2006;190(3-4):231-259.

84. Hijmans RJ, Cameron SE, Parra JL, Jones PG, Jarvis A. Very high resolution interpolated climate surfaces for global land areas. International Journal of Climatology: J. Roy. Meteor Soc. 
2005;25(15):1965-1978.

85. Ortego J, Gugger PF, Sork VL. Climatically stable landscapes predict patterns of genetic structure and admixture in the Californian canyon live oak. J Biogeogr. 2015;42(2):328-338.

86. Tsuda Y, Nakao K, Ide Y, Tsumura Y. The population demography of B. etulamaximowicziana, a cool temperate tree species in Japan, in relation to the last glacial period: its admixture like genetic structure is the result of simple population splitting not admixing. Mol Ecol. 2015;24(7):1403-1418.

87. Melo WA, Freitas CG, Bacon CD, Collevatti RG. The road to evolutionary success: insights from the demographic history of an Amazonian palm. Heredity. 2018;121(2):183-195.

88. Bates D, Maechler M, Bolker B, Walker S, Christensen RHB, Singmann H, Dai B, Grothendieck G, Green P, Bolker MB. Package 'Ime4'. Convergence. 2015;12(1):2.

89. Barton K, Barton MK. Package 'MuMIn'. R package version 1. 2019.

90. Kuznetsova A, Brockhoff PB, Christensen RHB. ImerTest package: tests in linear mixed effects models. J Stat Softw. 2017;82(13).

\section{Figures}

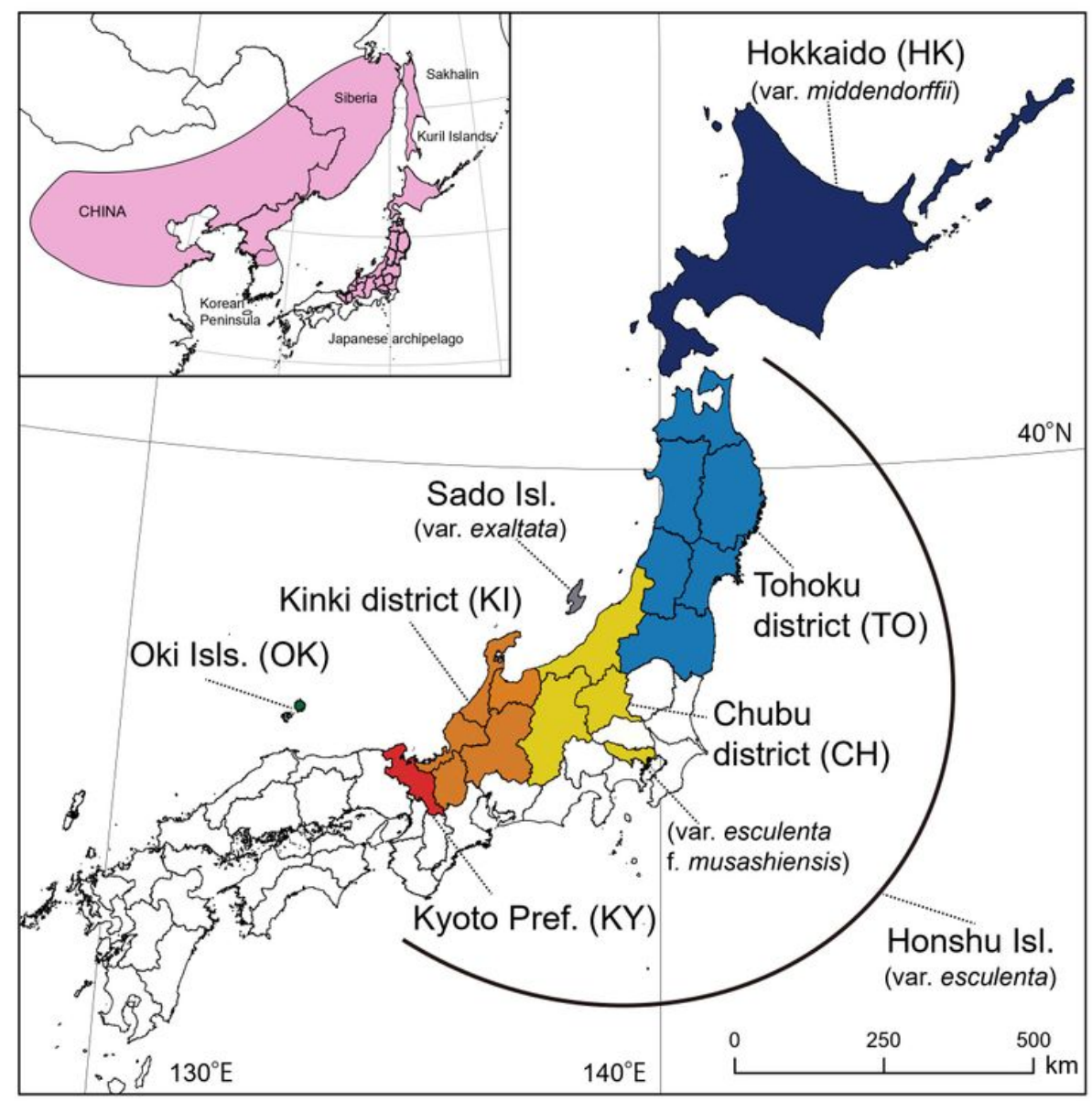


Figure 1

Distribution map of H. middendorffii in East Asia and the Japanese Archipelago (Barkalov 1987, 2009; Noguchi et al. 2004; Ohashi et al. 2015). The different colors in Japan indicate the geographic definition of regional groups of $\mathrm{H}$. middendorffii. These maps were created in ArcGIS 9.2 Desktop (ESRI, California, USA). Note: The designations employed and the presentation of the material on this map do not imply the expression of any opinion whatsoever on the part of Research Square concerning the legal status of any country, territory, city or area or of its authorities, or concerning the delimitation of its frontiers or boundaries. This map has been provided by the authors.

$L(K)$ (mean +- SD)

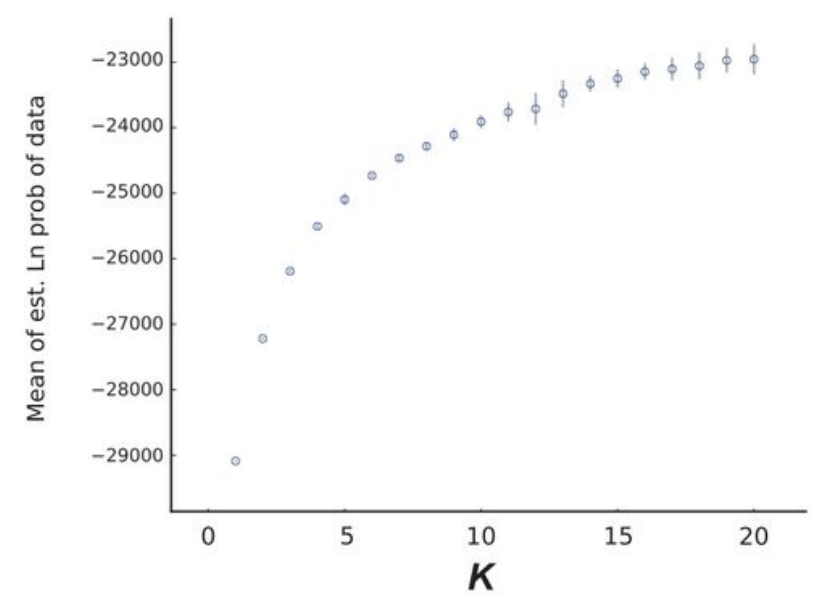

$\Delta K=\operatorname{mean}(|\mathrm{L} “(K)|) / \mathrm{sd}(\mathrm{L}(K))$

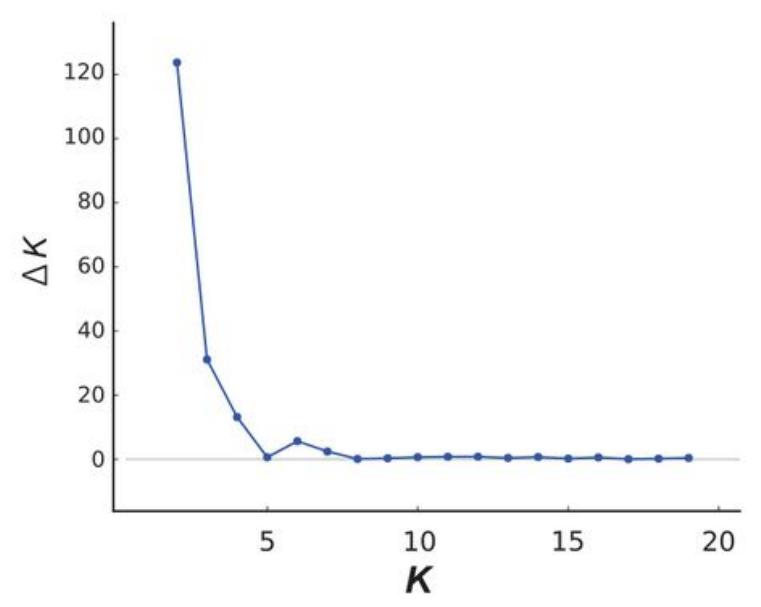

\section{Figure 2}

Values of the log-likelihood of the data, $\ln P(X \mid K)$, as a function of the number of clusters, $K$, resulting from the simulation in the STRUCTURE method (Pritchard et al. 2000), and (b) $\Delta K$, based on the rate of change of $\ln P(X \mid K)$ between successive $K$ values (Evanno et al. 2005). 


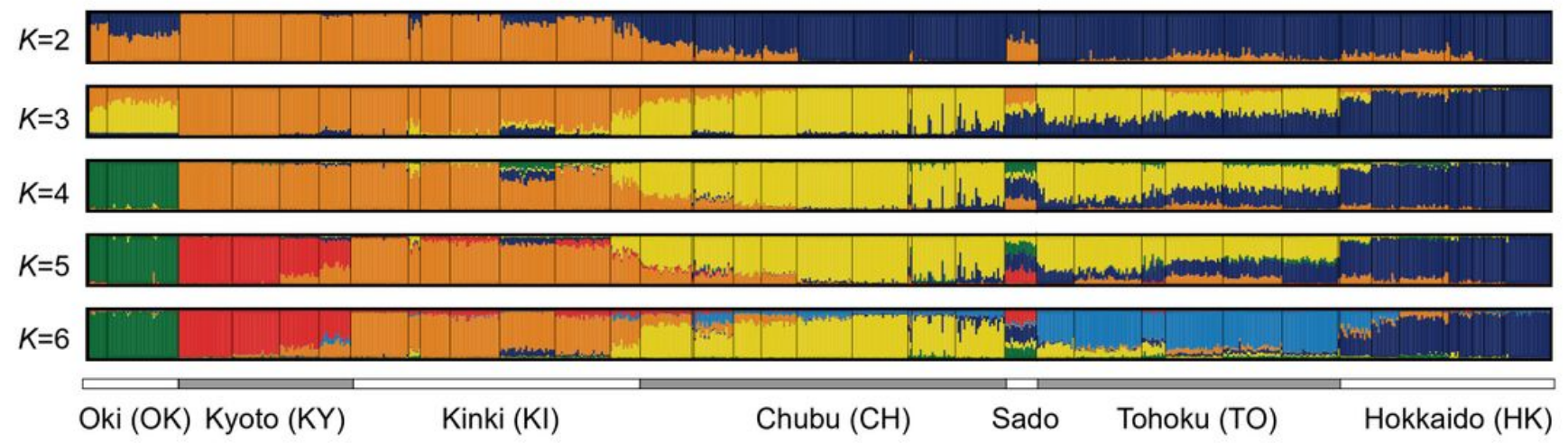

\section{Figure 3}

Individual clustering patterns inferred in STRUCTURE (Pritchard et al. 2000) for successive $K=2-6$. Each vertical bar in the histograms represents the proportion of cluster memberships in each individual. 


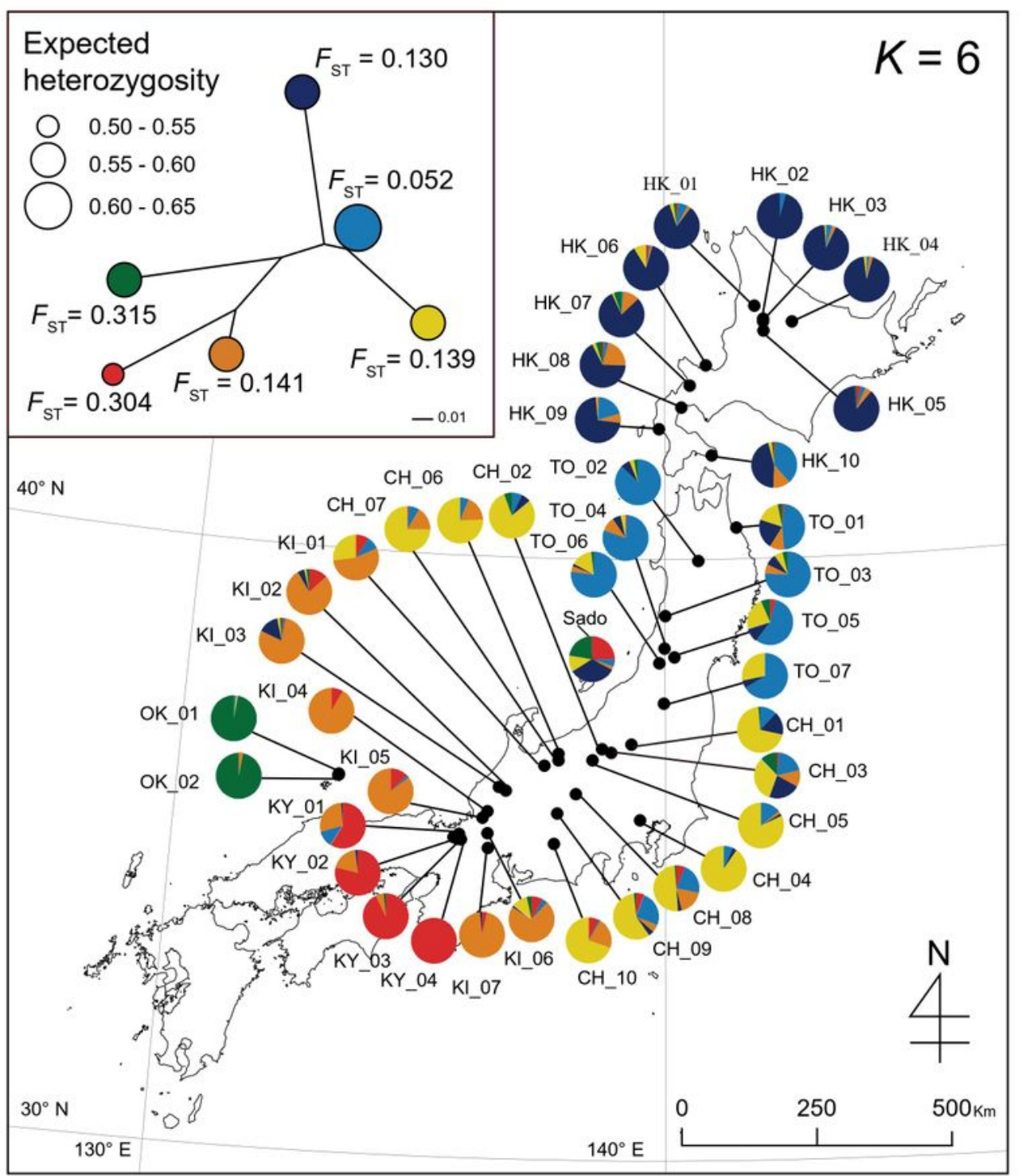

\section{Figure 4}

Distribution of cluster memberships at individual and population levels in the $41 \mathrm{H}$. middendorffii populations inferred by STRUCTURE (Pritchard et al. 2000). Geographic variation in population-level membership to gene pools $(K=6)$ is superimposed on the study area map. Geographic variation in population-level membership to gene pools is superimposed on the study area map. For each cluster, the expected heterozygosity within each pool is shown by the relative sizes of colored circles. FST values 
present the genetic drift undergone by each pool independent of the ancestral allele frequencies and the neighbor-joining tree related to the gene pools are shown. Note: The designations employed and the presentation of the material on this map do not imply the expression of any opinion whatsoever on the part of Research Square concerning the legal status of any country, territory, city or area or of its authorities, or concerning the delimitation of its frontiers or boundaries. This map has been provided by the authors.

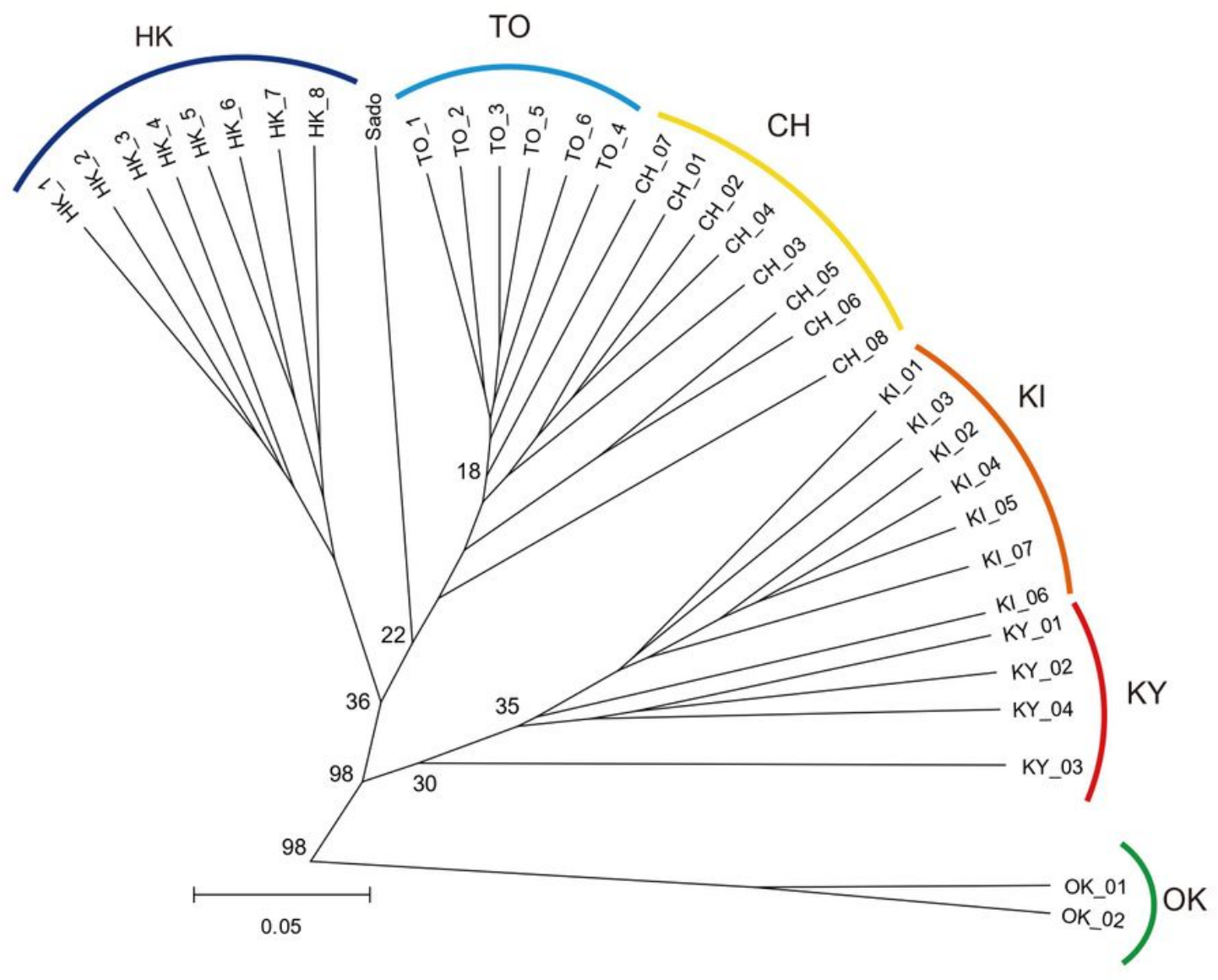

\section{Figure 5}

UPGMA tree was constructed based on Nei's DA distance (Nei and Takezaki, 1983) among the $35 \mathrm{H}$. middendorffii populations (sample size $>5$ ). Small numbers indicate bootstrap values, and population names are listed in Table S1. 


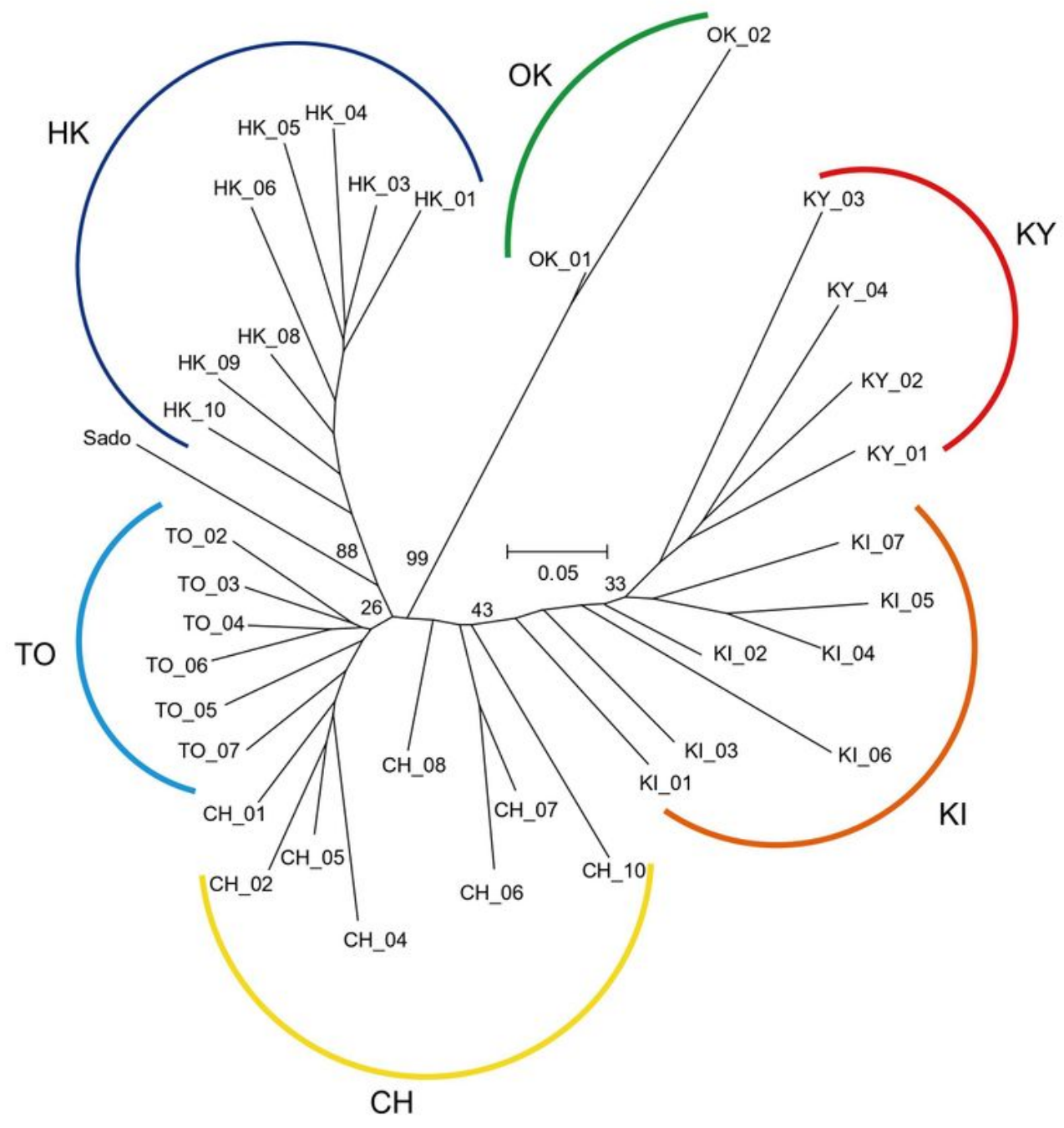

Figure 6

Neighbor-joining tree was constructed based on Nei's DA distance (Nei and Takezaki, 1983) among the 35 $\mathrm{H}$. middendorffii populations (sample size > 5). Small numbers indicate bootstrap values, and population names are as follows: (HK: Hokkaido Isl., TO: Tohoku district, $\mathrm{CH}$ : Chubu district, KI: Kinki district, KY: Kyoto pref., OK: Oki Isls.). 


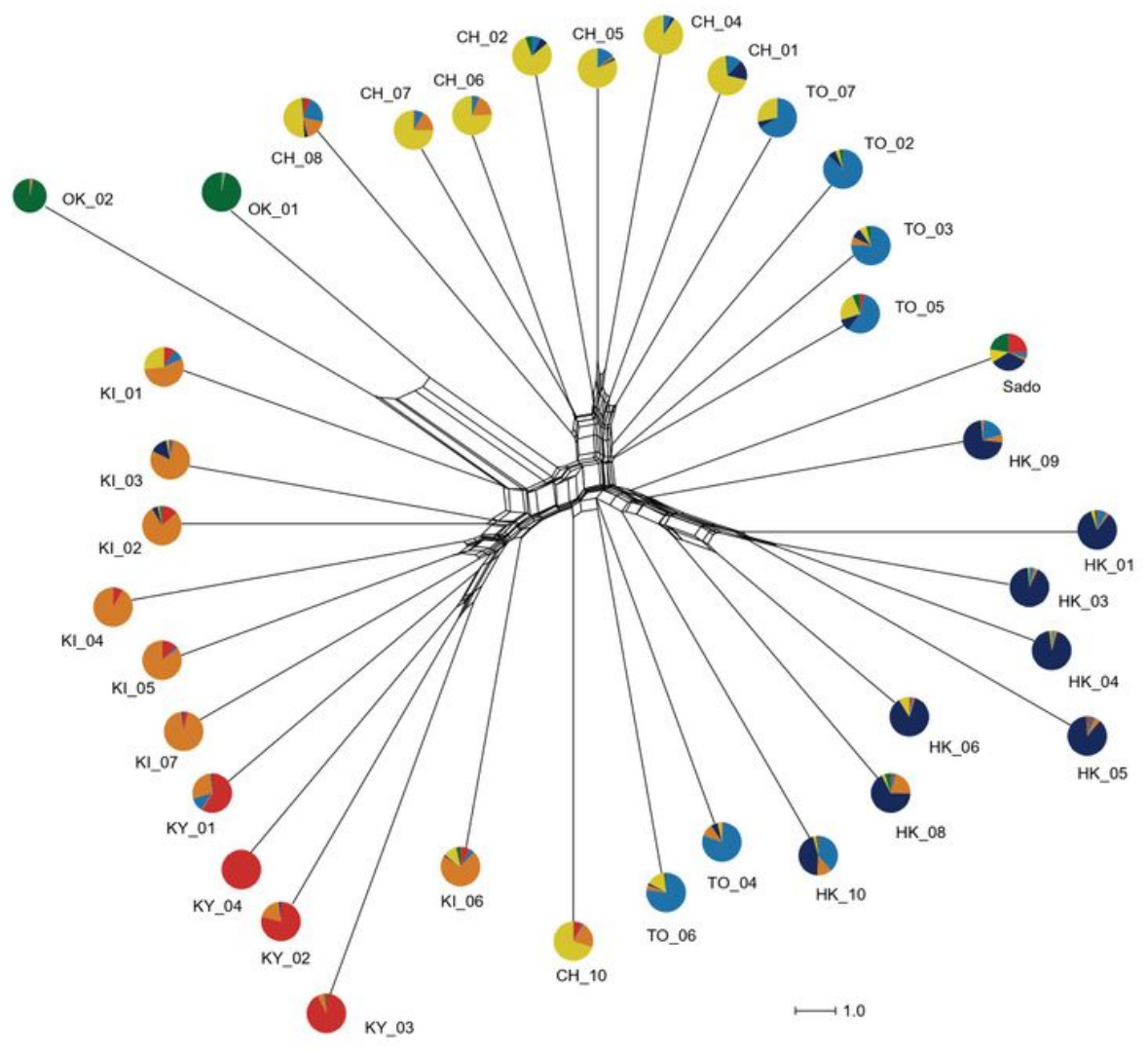

Figure 7

Population network based on Nei's DA distance (Nei and Takezaki, 1983), using software Splits Tree 4. The characters indicate the sampling populations (Table S1). The pie chart indicates the genetic structure in each population based on Figure 4. 

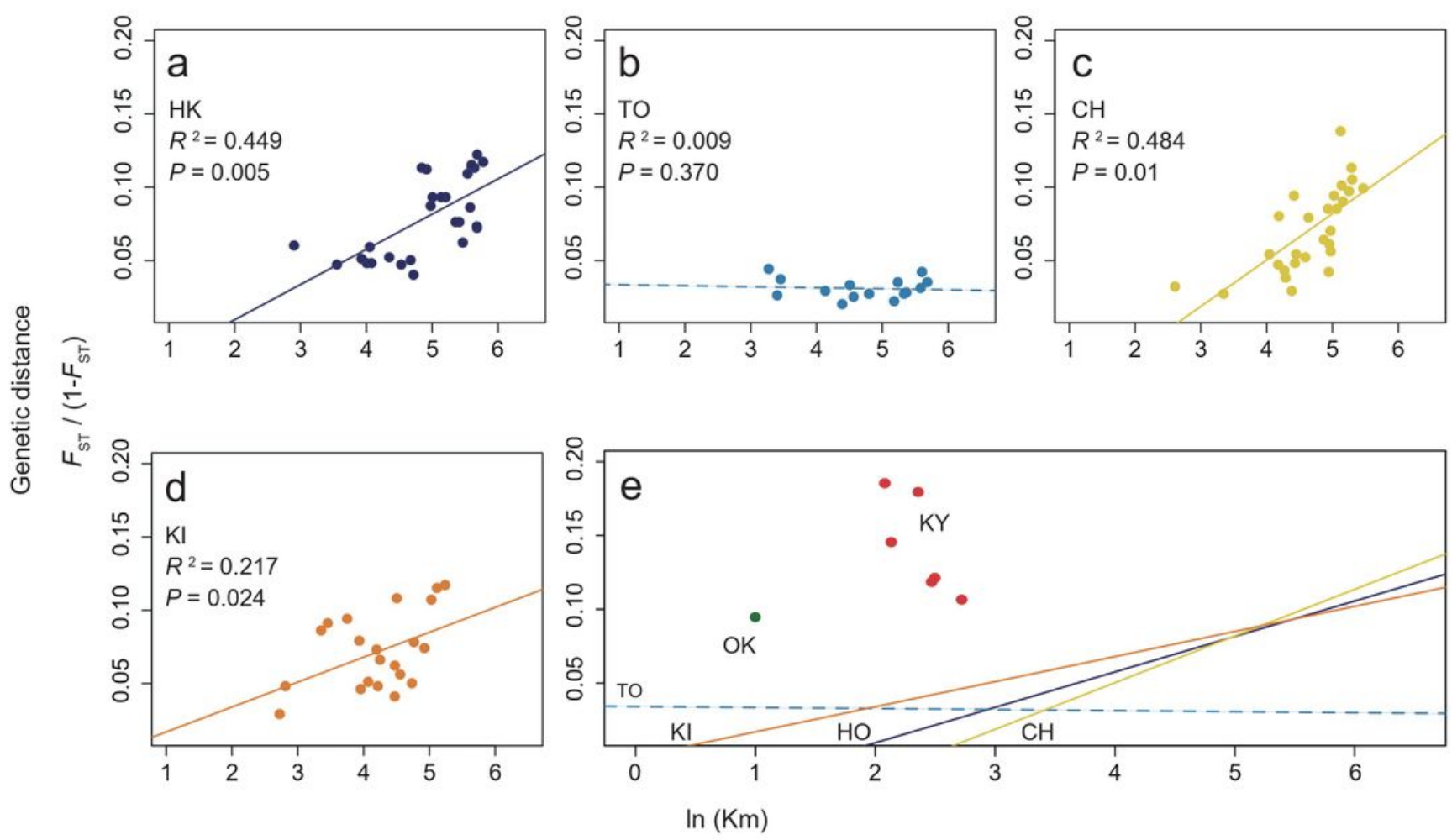

Geographic distance

Figure 8

The relationship between the pairwise genetic and log-transformed geographic distance matrices. The effect of isolation by distance was estimated for regional population (a) HK, (b) TO, (c) CH, (d) KI and (e) dots relationship within $\mathrm{OK}, \mathrm{KY}$, and regression lines of the others. $\mathrm{P}$ values and coefficient of determination R2 were calculated via Mantel tests with 999 permutations in GenAlEx.6.51 (Peakall and Smouse 2006). 

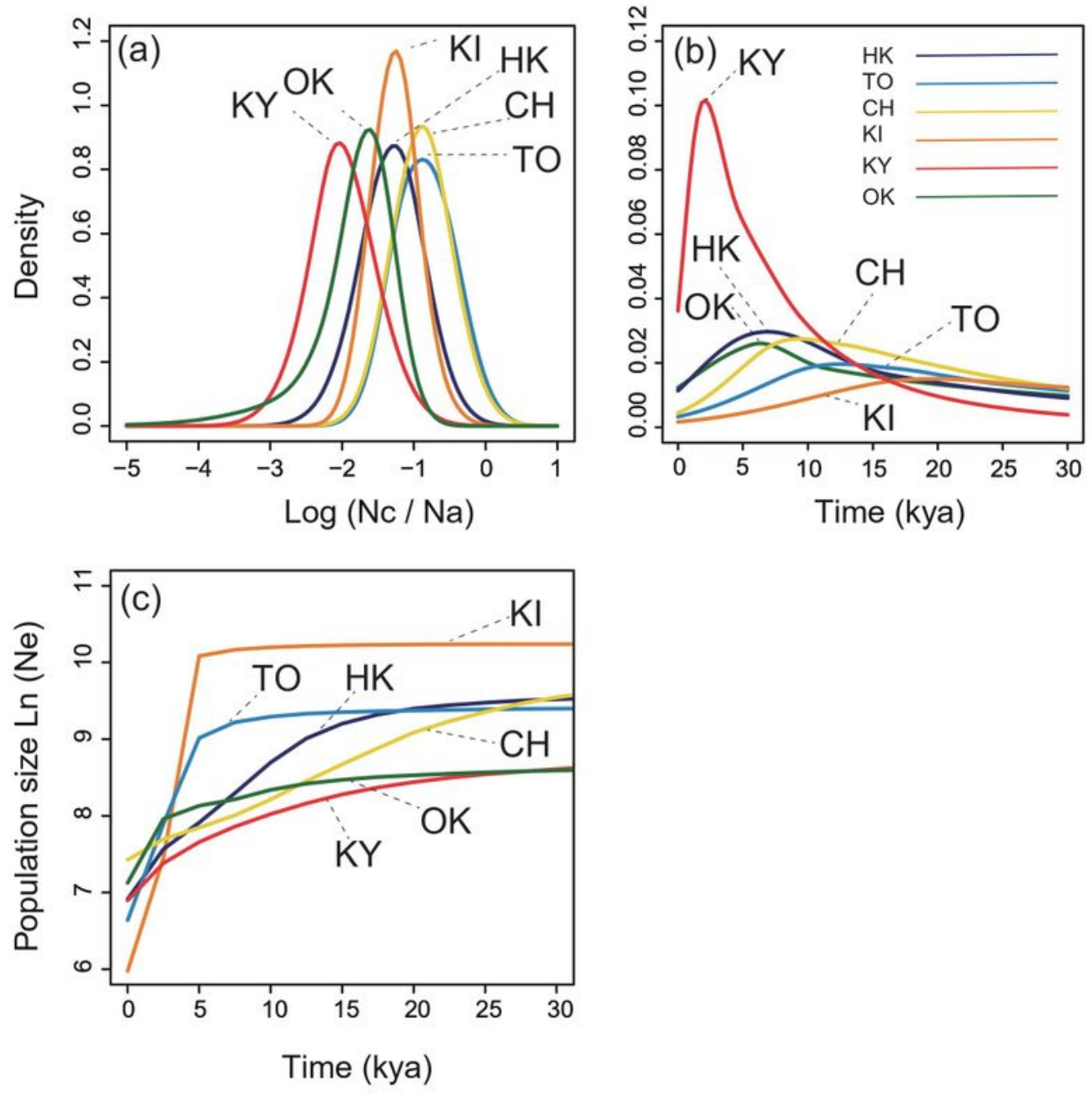

\section{Figure 9}

(a) Posterior probability density estimates for the intensity of changes in population sizes represented as the log-transformed ratio of the current to the ancestral population size $(\mathrm{Nc} / \mathrm{Na})$. Colors of density lines indicate the 6 regional populations. (b) Posterior probability density estimates of the time parameter for the populations that are inferred to have experienced population size changes. The parameter was converted to absolute time by assuming that the generation time of H. middendorffii is 10 years. (a) and 
(b) were provided by MSVAR 1.3 (Girod et al. 2011). (c) Effective population size changes through time estimated by VAREFF (Nikolic and Chevalet 2014).

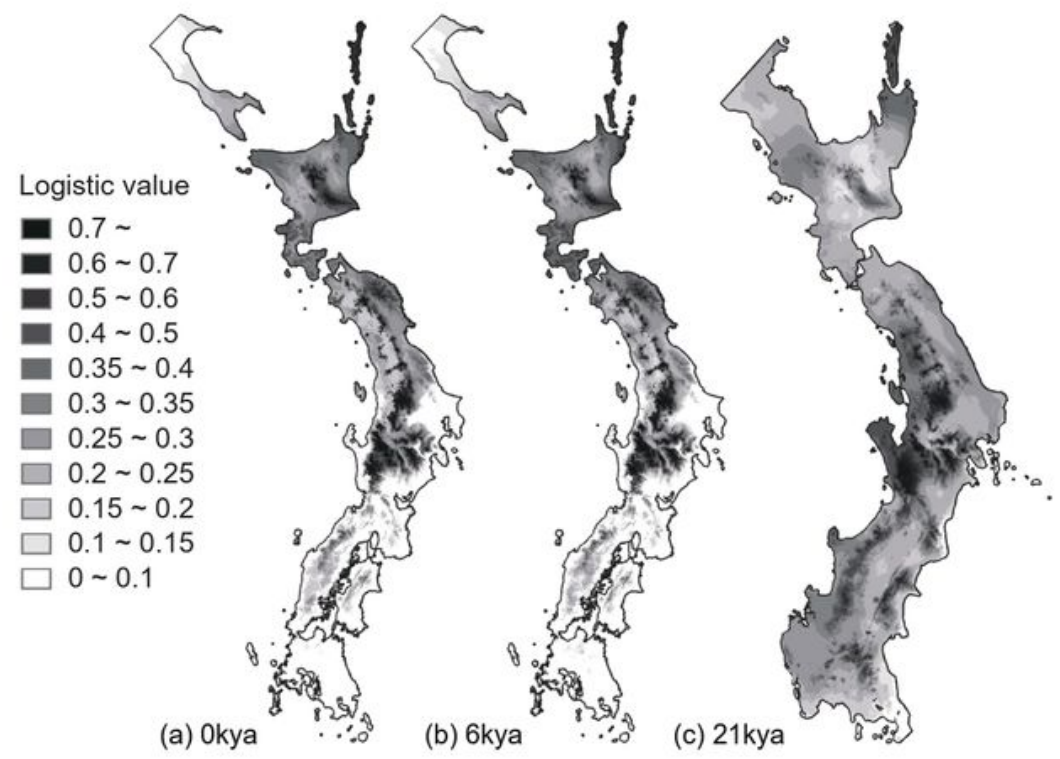

Figure 10

The predicted (a) 0kya (present), (b) 6kya (Holocene optimum) and (c) 21kya (LGM) distribution of H. middendorffii in Japan, estimated using MaxEnt 3.3.3 k (Phillips et al. 2006). Note: The designations employed and the presentation of the material on this map do not imply the expression of any opinion 
whatsoever on the part of Research Square concerning the legal status of any country, territory, city or area or of its authorities, or concerning the delimitation of its frontiers or boundaries. This map has been provided by the authors.
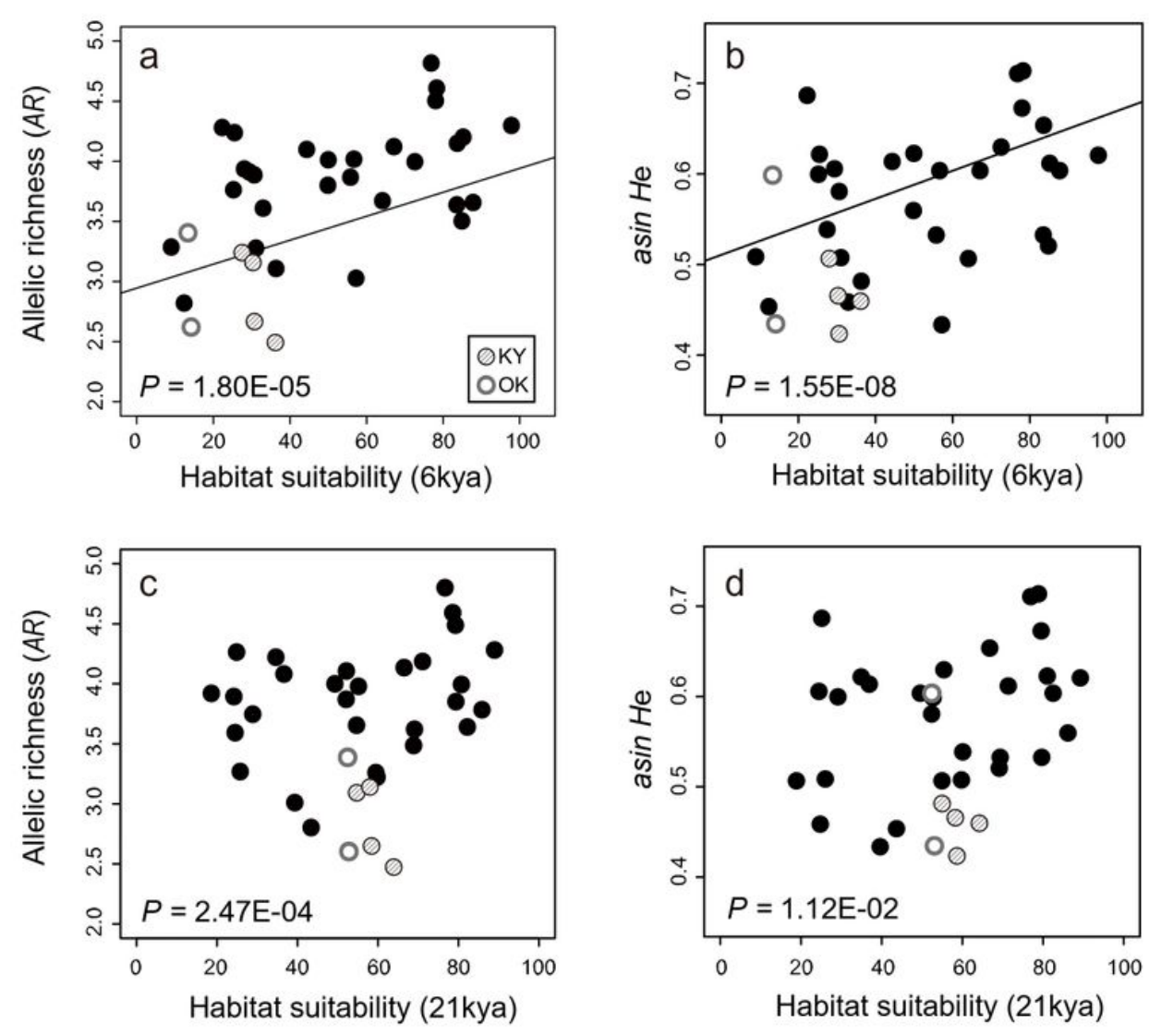

\section{Figure 11}

Genetic diversity values are plotted against population habitat suitability with regression line to the Holocene paleodistribution (a: AR, b: arcsin transformed He) and LGM paleodistribution (c: AR, d: arcsin transformed He, plot only) in the Japanese Archipelago. The plots with filled circles indicate the rear-edge populations in $\mathrm{KY}$ and $\mathrm{OK}$ regions. The predictor, habitat suitability, was evaluated by ring buffers with diameters of $5 \mathrm{~km}$.

\section{Supplementary Files}

This is a list of supplementary files associated with this preprint. Click to download.

- Supplementaryfile1.xlsx

- Supplementaryfile2.xlsx 